\title{
ISOLATION AND IDENTIFICATION OF HEAVY METAL TOLERANT BACTERIA FROM SUGARCANE INDUSTRIAL WASTEWATER
}

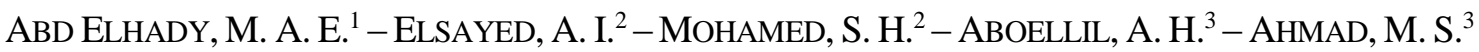 \\ ${ }^{1}$ Department of Agricultural Microbiology (Mallawy Agric. Res. Station), Soil, Water and \\ Environmental Research Institute, Agricultural Research Centre, P.O. Box, 12619, Giza, Egypt \\ ${ }^{2}$ Department of Agricultural Microbiology, Soil, Water and Environmental Research Institute, \\ Agricultural Research Centre, P.O. Box, 12619, Giza, Egypt \\ ${ }^{3}$ Department of Botany and Microbiology, Faculty of Science, Beni Suef University, Beni Suef, \\ Egypt \\ *Corresponding author \\ e-mail:dr.mohamed334455@gmail.com \\ (Received $14^{\text {th }}$ Sep 2019; accepted $4^{\text {th }}$ Dec 2019)
}

\begin{abstract}
One of the most serious problems of the environment is heavy metal toxicity originating from the industrial activities even in traces which harm the ecosystems. Initially a total of 30 isolates were screened on nutrient agar medium containing heavy metals: zinc, iron, cobalt, cadmium, copper and lead at four different concentrations $(25,50,75$ and $100 \mu \mathrm{g} / \mathrm{mL}$ in their salt form). Three isolates of Bacillus sp. were isolated from effluent industrial wastewater of Abu Kerqas Sugar Factory (27 $55^{\prime}$ 28.8" N $30^{\circ} 49^{\prime}$ 00.4" E), identified by using 16S rRNA gene and documented in GenBank as Bacillus spp. SMMAA-1 (LC472522), Bacillus cereus SMMAA-3 (LC472523), Bacillus altitudinis SMMAA-4 (LC472524). The bacterial isolates were selected based on their growth curve; IAA reaction and antibiosis effect were identified based on their morphological, biochemical characterization and utilization of carbohydrates as carbon sources. These isolates were evaluated for their abilities to bioremediate the toxic heavy metals. Results showed that bacteria present resistance to six heavy metals. B. cereus is more effective concerning its removal efficiency percentage for six heavy metals $\left(\mathrm{Zn}^{+2}, \mathrm{Fe}^{+2}\right.$, $\mathrm{Co}^{+2}, \mathrm{Cd}^{+2}, \mathrm{Cu}^{+2}$ and $\left.\mathrm{Pb}^{+2}\right)(94.77 \%)$ from Industrial Wastewater than Bacillus spp. (83.19\%) and $\mathrm{B}$. altitudinis $(83.21 \%)$. The highest removal efficiencies by Bacterial isolates were found with $\mathrm{Co}^{+2}, \mathrm{Cd}^{+2}$ and $\mathrm{Cu}^{+2}$ and the lowest removal biosorption were recorded with $\mathrm{Fe}^{+2}$.
\end{abstract}

Keywords: Bacillus spp., Bacillus cereus, Bacillus altitudinis, bioremediation, effluent wastewater, $16 \mathrm{~S}$ rRNA gene, GenBank

\section{Introduction}

Many organizations and scientists from various disciplines mentioned that the bioremediation can be used to break down the metal availability below the permissible limit. Most of them are in their advanced stages of developing different protocols and identifying a plethora of bacterial species to solve the issue (Kielak et al., 2017; Sardar et al., 2018). Exceedingly higher concentrations of heavy metals are a menace to human health due to their harmful effects such as genotoxicity towards the DNA and immunotoxicity as they are major irritants to the body. The genomic instability by these metals induces cancer (Leonard et al., 2004).

Heavy metals toxicity is significant environmental pollutants problem of increased significance for ecological, evolutionary, nutritional and environmental reasons (Nagajyoti et al., 2010; Jaishankar et al., 2014). Heavy metals water pollution one of serious important problems in world and Egypt. Heavy metals accumulations were observed in Egyptian 
cultivated such as soil, Nile River and air (Abbas and Kamel, 2004). Today, the quality of Nile water is a matter of serious concern due to exposure to increasing at an alarming rate multiple sources of heavy metals pollution including industrial, agricultural and domestic effluents. Effluent industrial wastewater is the main source of Nile pollution by heavy metals. The most commonly found heavy metals in wastewater include arsenic, cobalt, iron, cadmium, chromium, copper, lead, nickel, and zinc, all of which cause risks for human health and the environment (Lambert et al., 2000).

So, quick and easy removal and recovery of heavy metals from industrial wastewater at low cost are needed. Several conventional methods include precipitation, membrane filtration, ion exchange, electrochemical recovery; biological separation and adsorption are used to remove heavy metals from wastewater. Nevertheless, these methods unfriendly environmental, long processing times and high costs (Carolin et al., 2017). Nowadays, in light of this necessary for attractive alternative strategies low-cost, efficient and environmentally friendly methods instead of traditional to recover heavy metals from wastewater are needed (Moradi et al., 2015). The growing industrialization has spread worldwide and has left persistent toxic heavy metals, like chromium, nickel, lead, zinc, cadmium and copper in our ecosystem. These heavy metals tend to accumulate and deteriorate the environment. This is especially true for developing countries like China and India (Raja et al., 2008; Chauhan et al., 2017).

The bioremediation methods for reducing more of heavy metals in the environment have attracted importance. Living organisms were reported to able to absorb pollutants and remove heavy metals from the environment. Plants, fungi and microorganisms such as yeasts, bacteria, algae, and cyanobacteria are usually used for the bioremediation of heavy metals and recorded to be the best acceptable ones because they are easier to work with (Massoud et al., 2018). Several studies reported that bioremediation is the most effective management tool to manage the polluted environment and recover contaminated environment (Ahemad, 2012). Since heavy metals are ubiquitously present in our environment, microorganisms such as bacteria, yeast or fungi have developed mechanisms to removal contaminated soil and water via heavy metals (Kumar et al., 2011). Bioremediation includes some methods such as phytoremediation, biodegradation, bioventing (Dupont, 1993).

Assessment of microbes for their remediation potential in dealing with industrial pollutants is another point of interest where a bacterium or a fungus produces metabolites as their weapon of degradation (Pathak et al., 2017). Many bacterial strains contain genetic determinants of resistance to heavy metals such as $\mathrm{Hg}^{2+}, \mathrm{Ag}^{2+}, \mathrm{Cu}^{2+}$, $\mathrm{Ni}^{2+}, \mathrm{Cd}^{2+}$ and others (Karelova et al., 2011; Chauhan et al., 2017).

Several investigators have used different bacterial strains like Bacillus sp., Bacillus licheniformis, Bacillus thuringiensis, Pseudomonas sp., Staphylococcus aureus to for the biosorption as well as bioaccumulation of various metal ions like $\mathrm{Cr}(\mathrm{VI}), \mathrm{Ni}(\mathrm{II})$, $\mathrm{Zn}$ (II), Pb(II) etc. (Şahin and Ozturk, 2005; Tunali et al., 2006; Zhou et al., 2007; Ziagova et al., 2007; Wang et al., 2010; Akhter et al., 2017). Thus, the overall objective of the study is to enhance production of bacterial strains with high ability to uptake of heavy metals by different concentrations to helping in the reduction of Industrial wastewater effluent pollution of heavy metal. This emphasizes the importance and needs of carrying out extended testing for the compatibility of biosorption to heavy metals toxicity. It is more effective, cheap than traditional technologies of treating contaminated water with heavy metals, including precipitation, ion exchange or reverse osmosis still generate too large costs. 
This study aimed to isolation and identification of bacterial isolates that have ability to heavy metals biosorption and the role of bioremediation as technological method for uptake of six heavy metal ions from industrial wastewater effluent in Egypt to reduce the environmental pollutions.

\section{Materials and methods}

This study was conducted at both of Laboratory of Microbiology, Mallawy Agric. Res. Station, Dept. of Agric. Microbiology., Soil, Water and Environmental Research Institute, Agric. Res. Center, Giza, Egypt, and Central Lab., Faculty of Postgraduate Studies for Advanced Sciences, Beni Suef University. Molecular identification of the bacterial isolates was done in Microbiological Laboratory, Faculty of Agriculture, Zhejiang University, Hangzhou City, and East China during the period of 2017-2018.

\section{Industrial wastewater samples collection and preparation}

In this study, effluent industrial wastewater samples were collected from the site of the main drain of Abu Kerqas Sugar Factory (2755' 28.8' N 3049'00.4” E) (Fig. 1), El-Minia Governorate, March, 2017. Three samples of wastewater each $10 \mathrm{~L}$ per sample were collected in plastic jerry cans. Cans were previously sterilized by $75 \%$ ethanol, washed three times with wastewater to remove the residual effect of ethanol, and filled with the samples and then transferred immediately to the Microbiology Lab of Mallawy Agric. Res. Station. The three samples were mixed gently to obtain the main sample and kept in the refrigerator $\left(6 \pm 2{ }^{\circ} \mathrm{C}\right)$ for the further studies.

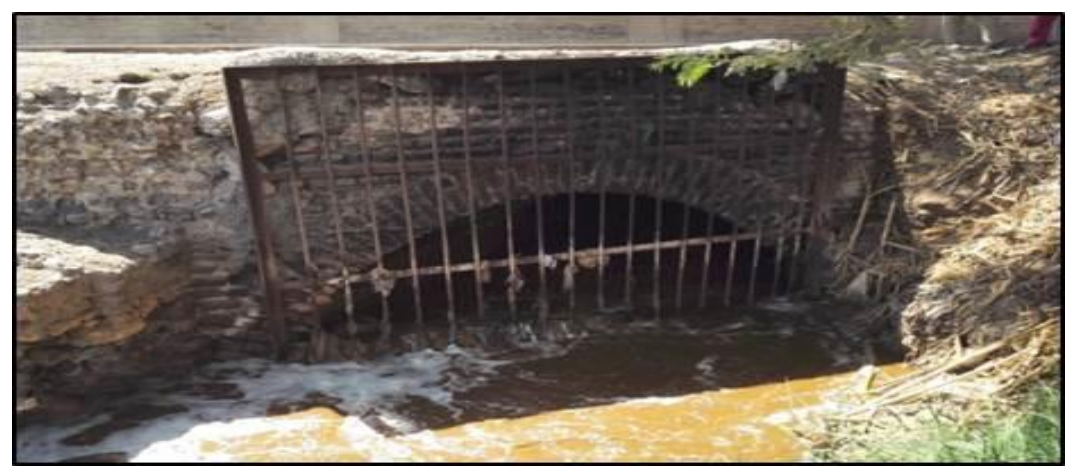

Figure 1. The main drain of Abu Kerqas Sugar Factory (27⒌ '28.8” N30 49'00.4” E)

\section{Determination of heavy metal concentrations in the wastewater samples}

Samples were taken from the main sample and sent to the Central Lab., Faculty of Postgraduate Studies for Advanced Sciences, Beni Suef University. The concentrations of heavy metals $\left(\mathrm{Zn}^{+2}, \mathrm{Fe}^{+2}, \mathrm{Co}^{+2}, \mathrm{Cd}^{+2}, \mathrm{Cu}^{+2}\right.$ and $\left.\mathrm{Pb}^{+2}\right)$ in samples were analyzed and determined by the Atomic Absorption Spectroscopy (Model: Agilent Technologies 200 series AA System) according to the method of EPA (2005).

\section{Bacteria isolation via streak plate technique}

Three dilutions (1.00, 0.50 and 0.25$)$ of each of the main sample and collected samples containing heavy metals, was done as described by Azad et al. (2013) to isolate 
the desired bacteria that have more tolerance to high concentration of heavy metals. This technique was applied to isolate some bacterial colonies able to grow in the presence of heavy metals. Two loops from the best dilution of the wastewater samples was taken and streaked onto sterile petri plates containing nutrient agar medium (NAM) as recorded by Marzan et al. (2017). Single colonies were selected, picked, purified and inoculated on NAM slant and coded as T1 up to T30. These single colonies were purified on NAM, and preserved on different plates or slants for further experiments.

\section{Tolerance of bacterial isolates to six heavy metals}

Six heavy metals: zinc $\left(\mathrm{Zn}^{+2}\right)$, iron $\left(\mathrm{Fe}^{+2}\right)$, cobalt $\left(\mathrm{Co}^{+2}\right)$, cadmium $\left(\mathrm{Cd}^{+2}\right)$, copper $\left(\mathrm{Cu}^{+2}\right)$ and lead $\left(\mathrm{Pb}^{+2}\right)$ were used in their salt structures as: $\mathrm{ZnSO}_{4}, \mathrm{FeSO}_{4} \cdot 7 \mathrm{H}_{2} \mathrm{O}, \mathrm{COC}_{12}$, $\mathrm{CdSO}_{4} \cdot 3 \mathrm{H} 2 \mathrm{O}, \mathrm{CuSO}_{4} \cdot 5 \mathrm{H}_{2} \mathrm{O}$ and $\mathrm{PbSO}_{4}$. According to the method of Vijayadeep and Sastry (2014) heavy metals salt solutions $(25,50,75,100 \mu \mathrm{g} / \mathrm{mL})$ were prepared in distilled water to obtain concentrations and sterilized by $0.2 \mu \mathrm{m}$ pore-size Millipore sterile filters. The bacterial isolates (T1, T2 and T3.....T30) were checked for the heavy metals tolerance using the agar well diffusion method as reported by Collins et al. (1985) in sterile NAM plates. On incubation of plates at $35-37{ }^{\circ} \mathrm{C}$ for $72 \mathrm{~h}$, the inhibition zones (the distance between the end of the zone and the edge of the well, $\mathrm{mm}$ ) were measured. Isolates showing a clear zone of $1 \mathrm{~mm}$ or less was considered as resistance (R) isolate according to Rani and Moreira (2010). The bacterial isolates which appeared resistance to the heavy metal ions at the all tested concentrations were recorded as (T1, T2, T3, T4, T5, T6, T7, T8, T10 and T18).

\section{Effect of industrial wastewater (IWW) toxicity on each of bacterial growth and indole acetic acid (IAA) production (color change) by the ten bacterial isolates}

The effects of IWW on the growth of the selected isolates (T1, T2, T3, T4, T5, T6, T7, T8, T10 and T18) were determined by growing the bacteria in nutrient broth medium (NBM) supplemented with sterile IWW (SIWW). IWW was sterilized by $0.2 \mu \mathrm{m}$ pore-size Millipore sterile filters. The cultures of bacterial isolates were grown in the presence of SIWW, and as a blank SIWW were taken out. One loop from each isolate culture was taken and inoculated in $100 \mathrm{~mL} \mathrm{NBM}$ and incubated under shaking condition (180 rpm) for $24 \mathrm{~h}$ at $30{ }^{\circ} \mathrm{C}$ as described by Priyadharshini and Kumar (2016). Then, $3.0 \mathrm{~mL}$ of the bacterial culture were added to each flask contained $100 \mathrm{~mL}$ of SIWW, mixed well and incubated as mentioned before. Bacterial growth was measured using a spectrophotometer (Spectronic 20 BauTchandLomp) at $620 \mathrm{~nm}$ as optical density (OD). The recorded data were taken after 1, 2, 3, 4, 5, 6 and 7 days from the incubation.

In case of effect of IWW on IAA produced by the bacterial isolates under investigation, the ten bacterial isolates were grown overnight in sterilized NB medium at $30{ }^{\circ} \mathrm{C}$ for $24 \mathrm{~h}$, and then $2.0 \mathrm{~mL}$ from each isolate were taken and inoculated with $5 \mathrm{~mL}$ SIWW to determine the degree of IAA by change of color visually as described by Glickmann and Dessaux (1995).

\section{Methods to determine the antibiosis activities of the ten bacterial isolates}

The antagonism of the bacterial isolates against F. solani, S. rolfsii and E. coli was performed using well diffusion method of Nedialkova and Naidenova (2005). The filtrate of E. coli was dropped (1-2 mL) in prepared holes of the NAM inoculated with 
ten bacterial isolates and incubated at $30{ }^{\circ} \mathrm{C}$ for $24-48 \mathrm{~h}$. Concerning to the antagonistic effect against F. solani and S. rolfsii, disc from each fungus growing on potato dextrose agar medium (PDA) was taken, and inoculated with the tested bacterial isolates. Three petri dishes per each of isolate and pathogen were used as replicates. The plates were incubated at $28{ }^{\circ} \mathrm{C}$ for 6 days, and the antagonistic activities were then recorded.

\section{Biological and molecular identification of the selected bacterial isolates}

The three bacterial isolates (T1, T3, and T4) which selected based on their tolerance to heavy metals; growth curve, IAA production and antagonistic effects were identified according to the methods described by Juni (1986) reported in Bergey's Manual of Systematic Bacteriology (1986, 2012).

Using 16S rRNA gene the identification of the three bacterial isolates was confirmed. NAM slants of the isolates were sent to Microbiology Laboratory, Faculty of Agriculture, Zhejiang University, Hangzhou City and East China. The genomic DNA of isolates was extracted using a Gene JET extraction kit (Thermo K0721) according to the Manufacturer's instructions.16S rRNA region was amplified with the following bacterial primers (F: 5'AGA GTT TGA TCC TGG CTC AG3' and R: 5'GGT TAC CTT GTT ACG ACTT3'). Thermal cycling consisted of initial denaturation at $94{ }^{\circ} \mathrm{C}$ for 2-5 min, followed by a cycle of denaturation at $95^{\circ} \mathrm{C}$ for $30 \mathrm{~s}$, annealing at $55-60{ }^{\circ} \mathrm{C}$ for $1 \mathrm{~min}$ and elongation at $72{ }^{\circ} \mathrm{C}$ for $60 \mathrm{~s}$, and finally, at $72{ }^{\circ} \mathrm{C}$ for $5-10 \mathrm{~min}$ for completion. The PCR amplification was performed using Gene JET Gel Extraction (ThermoK0701). Sequencing was performed using the ABI PRISM BigDyeTM Terminator Cycle Sequencing Kits, ABI PRISM 3730XL Analyzer (96 capillary type) sequencer (Applied Biosystems), MJ Research PTC-225 Peltier Thermal Cycler, DNA polymerase (FS enzyme) (Applied Biosystems). The DNA sequences of the PCR product of the $16 \mathrm{~S}$ rRNA gene of the three bacterial isolates were through the BLAST P program which available on the National Center for Biotechnology Information website http://blast.ncbi.nlm.nih.gov/Blastcgi? PROGRAM=blast $\mathrm{p}$ and PAGE TYPE=BLAST Search and LINK - LOC=blast home (Altschul et al., 1990).

\section{Selected bacterial isolates (T1) Bacillus spp., (T3) B. cereus and (T4) B. altitudinis effects}

The effects of the selected isolates (Bacillus spp., B. cereus and B. altitudinis) were tested for their ability to alleviate or eliminate the heavy metal concentrations for industrial wastewater effluent.

$1 \mathrm{ml}$ from each bacterial isolate that growing in nutrient broth medium was inoculated to flasks contained $100 \mathrm{ml}$ of sterilized industrial wastewater (SIWW). The flasks were incubated in a shaker for $24 \mathrm{~h}$ at $30 \pm 2{ }^{\circ} \mathrm{C}$ under static conditions as mentioned by Priyadharshini and Kumar (2016). The flasks were filtered (Whatman filter paper No.1) then the samples were received to the Central Lab., Faculty of Postgraduate Studies for Advanced Sciences, Beni Suef University to determinate the heavy metals concentrations for each sample. The percentage of removal heavy metals $\left(\mathrm{Zn}^{+2}, \mathrm{Fe}^{+2}, \mathrm{Co}^{+2}, \mathrm{Cd}^{+2}, \mathrm{Cu}^{+2}\right.$ and $\left.\mathrm{Pb}^{+2}\right)$ was calculated as Equation 1 and that recoded by Bakar et al. (2013) as follows:

$$
\text { Removal efficiency } \%=\frac{\text { Initial metal conc. }- \text { Final metal conc. }}{\text { Initial metal conc. }} \times 100
$$




\section{Statistical analysis}

The data were prepared by mean \pm standard deviation $(n=3)$ and carried out as a randomized complete design (Snedecor and Cochran, 1980) using LSD test to compare means of treatments in investigation. Statistical significance was defined as $\mathrm{P}<0.05$. Mean values of three replicates followed by the same letters in each column are not significantly different $(\mathrm{P}>0.05)$ (Duncan multiple range test).

\section{Results and discussion}

This study was designed to isolate some promising bacteria able to tolerant the high levels of heavy metals in EIWW in a trail to decrease or remove the heavy metals present in the EIWW. Therefore, determination of heavy metals concentration in EIWW samples was conducted for the six heavy metal ions $\left(\mathrm{Zn}^{+2}, \mathrm{Fe}^{+2}, \mathrm{Co}^{+2}, \mathrm{Cd}^{+2}, \mathrm{Cu}^{+2}\right.$ and $\mathrm{Pb}^{+2}$ ) that threatening the environments, human, plants and animals.

\section{Heavy metal concentrations in the EIWW samples}

Data illustrated in Table 1, showed that the concentrations of the six selected heavy metal ions in EIWW samples. The concentrations were ranged from $6 \mathrm{ppm}\left(\mathrm{Zn}^{+2}\right)$ to $1.4 \mathrm{ppm}\left(\mathrm{Co}^{+2}\right)$. It was noted that all tested heavy metals presented in high concentration compared to permissible limits excepted for $\mathrm{Fe}^{+2}$ ion which was the lowest one $(2.1 \mathrm{ppm})$ compared to permissible rate $(3.0 \mathrm{ppm})$. Also, the concentrations of $\mathrm{Co}^{+2}$, $\mathrm{Cd}^{+2}$ and $\mathrm{Pb}^{+2}$ heavy metals were more folds than the guidelines and standers of $\mathrm{WHO}$, therefore, these ions were considered as the highest toxic ions. This notes in harmony with that reported by Rajendran and Gunasekaran (2007) and Murthy et al. (2012).

Table 1. Heavy metals concentrations in the main EIWW sample collected from Abu Kerqas Sugar Factory, El-Minia, Egypt, compared to permissible rate (ppm) according the guidelines and standers of WHO

\begin{tabular}{c|c|c|c}
\hline Metals & Conc. (ppm) & Permissible rate (ppm) & References \\
\hline $\mathrm{Zn}^{+2}$ & 6.0 & 5.000 & WHO (1984) \\
$\mathrm{Fe}^{+2}$ & 2.1 & 3.000 & WHO (2006) \\
$\mathrm{Co}^{+2}$ & 1.4 & 0.010 & WHO (2003) \\
$\mathrm{Cd}^{+2}$ & 1.8 & 0.005 & WHO $(1984)$ \\
& & 0.003 & WHO $(2003)$ \\
$\mathrm{Cu}^{+2}$ & 1.5 & 1.000 & WHO $(1984,2003)$ \\
& & 1.300 & WHO $(2006)$ \\
$\mathrm{pb}^{+2}$ & 1.9 & 0.050 & WHO $(1984,2003)$ \\
\hline
\end{tabular}

$\mathrm{WHO}=$ World Health Organization

\section{Bacteria isolation via streak plate technique using NA media supplemented with different dilutions of EIWW}

Data represented in Figure 2 show the presence of single colonies exhibited Bacilluslike species cultural properties grown on NAM inoculated with different dilutions of EIWW. The lowest concentration $(0.25 \mathrm{~mL})$ from (EIWW) have purified single separated colonies compared that of 0.50 and $1.00 \mathrm{~mL}$. The last two dilutions showed crowded, compacted and irregular colonies on the NAM which are not easily 
distinguished. Therefore, it has been observed that of the dilution of $0.25 \mathrm{~mL}$ was considered the best dilution to obtain the single separated colonies which were easily selected, picked, purified and easily distinguished. A number of 30 isolates were picked, purified and coded symbols of T1, T2, T3 and T4 ...to T30.

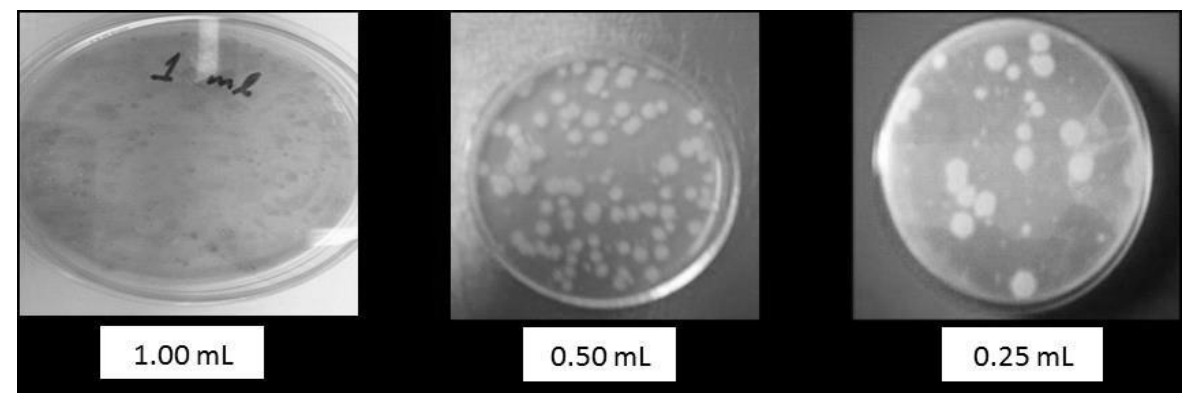

Figure 2. Cultural properties of the isolated bacteria grown on different dilutions of EIWW

\section{Tolerance of bacterial isolates to six heavy metals}

The bacterial isolates were coded as T1 up to T30, and evaluated for their abilities to tolerant a number of six heavy metals $\left(\mathrm{Zn}^{+2}, \mathrm{Fe}^{+2}, \mathrm{Co}^{+2}, \mathrm{Cd}^{+2}, \mathrm{Cu}^{+2}\right.$ and $\left.\mathrm{Pb}^{+2}\right)$ at four concentrations $(25,50,75$ and $100 \mu \mathrm{g} / \mathrm{mL})$ as shown in Table 2. Based on the diameter of inhibition zones, the isolates were classified as sensitive or tolerant to each heavy metal ion and its concentration. The isolates were varied in their abilities to tolerant the heavy metal concentrations. The isolates that able to grow at concentrations of metal ions at 25, 50, 75 and $100(\mu \mathrm{g} / \mathrm{mL})$ were considered as tolerant as they showed a clear inhibition zone of $1 \mathrm{~mm}$ (Fig. 3) or less according to (Rani et al., 2010). Data in Table 2, showed that $\mathrm{T} 10$ isolate appeared tolerance to $\mathrm{Cd}^{+2}, \mathrm{Cu}^{+2}$ and $\mathrm{Pb}^{+2}$, while $\mathrm{T} 18$ isolate were tolerant to $\mathrm{Zn}^{+2}, \mathrm{Fe}^{+2}$ and $\mathrm{Co}^{+2}$. Results also showed that the highest tolerant bacterial isolates to the four concentrations of the six for heavy metal ions were T1, T2, T3, T4, T5, T6, T7, and T8. On the other direction, T23 isolate appeared sensitivity to all tested heavy metal ions except for with $\mathrm{Pb}$, as it was tolerant (Table 2).

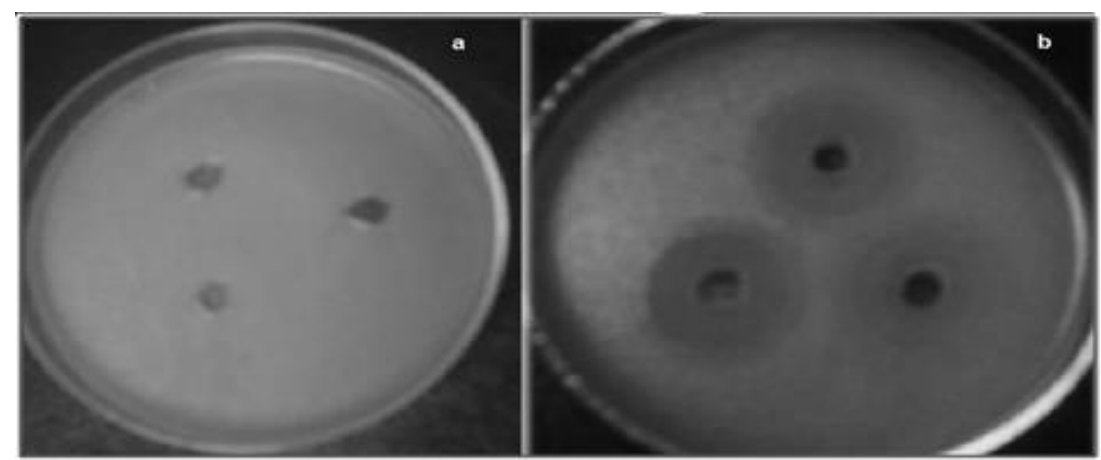

Figure 3. Tolerance of the bacterial isolate to heavy metals [resistant (a) and clear of inhibition zone as sensitive (b)]

At the lowest concentration $(25 \mu \mathrm{g} / \mathrm{mL})$ of all six heavy metal ions, all bacterial isolates were tolerant except for the heavy metal ion $\left(\mathrm{Pb}^{+2}\right)$. These results are in agreed with that reported by Malik and Jaiswal (2000), who showed that acceptable 
concentration of metal ions, which could be used for distinguishing metal tolerant and metal-sensitive bacteria, strains able to grow at concentrations of metal ions at and above $1.0 \mathrm{mM}$ were considered resistant. Based on the experimental findings, the heavy metal-tolerant bacteria could be selected as especially promising microorganisms for bioremediation application of heavy metals polluted places.

\section{Effect of EIWW toxicity on each of bacterial growth and indole acetic acid (IAA) produced by bacterial isolates}

Effects of SIWW on bacterial growth, representing in each of growth curve [expressed as optical density (OD) $(\lambda=620 \mathrm{~nm})$ as recommended by Priyadharshini and Kumar (2016), and bacterial growth periods [1, 2, 3, 4, 5, 6 and 7 days] of ten isolates (T1, T2, T3, T4, T5, T6, T7, T8, T10 and T18) was carried out.

Table 2. Tolerance of bacterial isolates to six heavy metals expressed as zone of inhibition

\begin{tabular}{|c|c|c|c|c|c|c|c|c|c|c|c|c|}
\hline \multirow{3}{*}{ ICs } & \multicolumn{12}{|c|}{ Heavy metal concentrations $(\mu \mathrm{g} / \mathrm{mL})$} \\
\hline & 25 & 50 & 75 & 100 & 25 & 50 & 75 & 100 & 25 & 50 & 75 & 100 \\
\hline & \multicolumn{4}{|c|}{$\mathbf{Z n}^{+2}$} & \multicolumn{4}{|c|}{$\mathrm{Fe}^{+2}$} & \multicolumn{4}{|c|}{$\mathrm{Co}^{+2}$} \\
\hline T1 & $\mathrm{R}$ & $\mathrm{R}$ & $\mathrm{R}$ & $\mathrm{R}$ & $\mathrm{R}$ & $\mathrm{R}$ & $\mathrm{R}$ & $\mathrm{R}$ & $\mathrm{R}$ & $\mathrm{R}$ & $\mathrm{R}$ & $\mathrm{R}$ \\
\hline $\mathbf{T} 2$ & $\mathrm{R}$ & $\mathrm{R}$ & $\mathrm{R}$ & $\mathrm{R}$ & $\mathrm{R}$ & $\mathrm{R}$ & $\mathrm{R}$ & $\mathrm{R}$ & $\mathrm{R}$ & $\mathrm{R}$ & $\mathrm{R}$ & $\mathrm{R}$ \\
\hline T3 & $\mathrm{R}$ & $\mathrm{R}$ & $\mathrm{R}$ & $\mathrm{R}$ & $\mathrm{R}$ & $\mathrm{R}$ & $\mathrm{R}$ & $\mathrm{R}$ & $\mathrm{R}$ & $\mathrm{R}$ & $\mathrm{R}$ & $\mathrm{R}$ \\
\hline T4 & $\mathrm{R}$ & $\mathrm{R}$ & $\mathrm{R}$ & $\mathrm{R}$ & $\mathrm{R}$ & $\mathrm{R}$ & $\mathrm{R}$ & $\mathrm{R}$ & $\mathrm{R}$ & $\mathrm{R}$ & $\mathrm{R}$ & $\mathrm{R}$ \\
\hline T5 & $\mathrm{R}$ & $\mathrm{R}$ & $\mathrm{R}$ & $\mathrm{R}$ & $\mathrm{R}$ & $\mathrm{R}$ & $\mathrm{R}$ & $\mathrm{R}$ & $\mathrm{R}$ & $\mathrm{R}$ & $\mathrm{R}$ & $\mathrm{R}$ \\
\hline T6 & $\mathrm{R}$ & $\mathrm{R}$ & $\mathrm{R}$ & $\mathrm{R}$ & $\mathrm{R}$ & $\mathrm{R}$ & $\mathrm{R}$ & $\mathrm{R}$ & $\mathrm{R}$ & $\mathrm{R}$ & $\mathrm{R}$ & $\mathrm{R}$ \\
\hline $\mathbf{T} 7$ & $\mathrm{R}$ & $\mathrm{R}$ & $\mathrm{R}$ & $\mathrm{R}$ & $\mathrm{R}$ & $\mathrm{R}$ & $\mathrm{R}$ & $\mathrm{R}$ & $\mathrm{R}$ & $\mathrm{R}$ & $\mathrm{R}$ & $\mathrm{R}$ \\
\hline T8 & $\mathrm{R}$ & $\mathrm{R}$ & $\mathrm{R}$ & $\mathrm{R}$ & $\mathrm{R}$ & $\mathrm{R}$ & $\mathrm{R}$ & $\mathrm{R}$ & $\mathrm{R}$ & $\mathrm{R}$ & $\mathrm{R}$ & $\mathrm{R}$ \\
\hline T9 & $\mathrm{R}$ & $\mathrm{R}$ & $\mathrm{R}$ & $\mathrm{R}$ & $3.5(\mathrm{~S})^{*}$ & $3.7(\mathrm{~S})$ & $3.5(\mathrm{~S})$ & $3.9(\mathrm{~S})$ & $\mathrm{R}$ & $\mathrm{R}$ & $\mathrm{R}$ & $\mathrm{R}$ \\
\hline T10 & $\mathrm{R}$ & $\mathrm{R}$ & $\mathrm{R}$ & $\mathrm{R}$ & $3.5(\mathrm{~S})$ & $4(S)$ & $3.5(\mathrm{~S})$ & $3.7(\mathrm{~S})$ & $\mathrm{R}$ & $\mathrm{R}$ & $\mathrm{R}$ & $\mathrm{R}$ \\
\hline T11 & $\mathrm{R}$ & $\mathrm{R}$ & $1,(\mathrm{~S})$ & $1,(\mathrm{~S})$ & $\mathrm{R}$ & $\mathrm{R}$ & $\mathrm{R}$ & $0.5(\mathrm{~S})$ & $1(\mathrm{~S})$ & $1(\mathrm{~S})$ & $1(\mathrm{~S})$ & $1(\mathrm{~S})$ \\
\hline T12 & $\mathrm{R}$ & $\mathrm{R}$ & $\mathrm{R}$ & $0.5(\mathrm{~S})$ & $\mathrm{R}$ & $\mathrm{R}$ & $\mathrm{R}$ & $1,(\mathrm{~S})$ & $\mathrm{R}$ & $\mathrm{R}$ & $\mathrm{R}$ & $\mathrm{R}$ \\
\hline T13 & $2,(\mathrm{~S})$ & $2(\mathrm{~S})$ & $2(\mathrm{~S})$ & $2.6(\mathrm{~S})$ & $1.6(\mathrm{~S})$ & $1.6(\mathrm{~S})$ & $1.6(\mathrm{~S})$ & $1.6(\mathrm{~S})$ & $\mathrm{R}$ & $\mathrm{R}$ & $\mathrm{R}$ & $\mathrm{R}$ \\
\hline T14 & $\mathrm{R}$ & $\mathrm{R}$ & $\mathrm{R}$ & $\mathrm{R}$ & $1.4(\mathrm{~S})$ & $2.6(\mathrm{~S})$ & $2.6(\mathrm{~S})$ & $2.6(\mathrm{~S})$ & $1.6(\mathrm{~S})$ & $1.6(\mathrm{~S})$ & $1.6(\mathrm{~S})$ & $1.6(\mathrm{~S})$ \\
\hline T15 & $\mathrm{R}$ & $2(\mathrm{~S})$ & $1.3(\mathrm{~S})$ & $1.9(\mathrm{~S})$ & $1.8(\mathrm{~S})$ & $2.1(\mathrm{~S})$ & $1.8(\mathrm{~S})$ & $2.5(\mathrm{~S})$ & $\mathrm{R}$ & $2(\mathrm{~S})$ & $1(\mathrm{~S})$ & $1.3(\mathrm{~S})$ \\
\hline T16 & $\mathrm{R}$ & $0.9(\mathrm{R})$ & $1.2(\mathrm{~S})$ & $1.3(\mathrm{~S})$ & $2.2(\mathrm{~S})$ & $3.1(\mathrm{~S})$ & $2,(\mathrm{~S})$ & $2.3(\mathrm{~S})$ & $\mathrm{R}$ & $0.9(\mathrm{~S})$ & $0.9(\mathrm{~S})$ & $1.1(\mathrm{~S})$ \\
\hline T17 & $\mathrm{R}$ & $\mathrm{R}$ & $\mathrm{R}$ & $\mathrm{R}$ & $\mathrm{R}$ & $\mathrm{R}$ & $\mathrm{R}$ & $\mathrm{R}$ & $1.2(\mathrm{~S})$ & $1.2(\mathrm{~S})$ & $1.2(\mathrm{~S})$ & $1.2(\mathrm{~S})$ \\
\hline T18 & $\mathrm{R}$ & $\mathrm{R}$ & $\mathrm{R}$ & $\mathrm{R}$ & $\mathrm{R}$ & $\mathrm{R}$ & $\mathrm{R}$ & $\mathrm{R}$ & $\mathrm{R}$ & $\mathrm{R}$ & $\mathrm{R}$ & $\mathrm{R}$ \\
\hline T19 & $1(\mathrm{~S})$ & $1,(\mathrm{~S})$ & $1,(\mathrm{~S})$ & $1,(\mathrm{~S})$ & $\mathrm{R}$ & $\mathrm{R}$ & $0.7(\mathrm{~S})$ & $0.7(\mathrm{~S})$ & $1.9(\mathrm{~S})$ & $1.9(\mathrm{~S})$ & $1.9(\mathrm{~S})$ & $1.9(\mathrm{~S})$ \\
\hline $\mathbf{T} 20$ & $\mathrm{R}$ & $\mathrm{R}$ & $1,(\mathrm{~S})$ & $2,(\mathrm{~S})$ & $1.3(\mathrm{~S})$ & $1.7(\mathrm{~S})$ & $1.1(\mathrm{~S})$ & $2.5(\mathrm{~S})$ & $1.5(\mathrm{~S})$ & $1.5(\mathrm{~S})$ & $1.9(\mathrm{~S})$ & $2,(\mathrm{~S})$ \\
\hline $\mathbf{T} 21$ & $\mathrm{R}$ & $\mathrm{R}$ & $0.9(\mathrm{~S})$ & $1.8(\mathrm{~S})$ & $\mathrm{R}$ & $\mathrm{R}$ & $0.5(\mathrm{~S})$ & $0.5(\mathrm{~S})$ & $\mathrm{R}$ & $\mathrm{R}$ & $1(\mathrm{~S})$ & $1(\mathrm{~S})$ \\
\hline $\mathbf{T} 22$ & $\mathrm{R}$ & $\mathrm{R}$ & $\mathrm{R}$ & $0.9(\mathrm{~S})$ & $\mathrm{R}$ & $\mathrm{R}$ & $\mathrm{R}$ & $1.6(\mathrm{~S})$ & $\mathrm{R}$ & $\mathrm{R}$ & $\mathrm{R}$ & $1(\mathrm{~S})$ \\
\hline $\mathbf{T} 23$ & $1.9(\mathrm{~S})$ & $1.9(\mathrm{~S})$ & $2,(\mathrm{~S})$ & $2,(\mathrm{~S})$ & $1.2(\mathrm{~S})$ & $1.2(\mathrm{~S})$ & $1.5(\mathrm{~S})$ & $1.7(\mathrm{~S})$ & $1.2(\mathrm{~S})$ & $1.2(\mathrm{~S})$ & $1.8(\mathrm{~S})$ & $1.8(\mathrm{~S})$ \\
\hline T24 & $\mathrm{R}$ & $\mathrm{R}$ & $\mathrm{R}$ & $\mathrm{R}$ & $2.6(\mathrm{~S})$ & $3.6(\mathrm{~S})$ & $3.6(\mathrm{~S})$ & $3.6(\mathrm{~S})$ & $1.1(\mathrm{~S})$ & $1.1(\mathrm{~S})$ & $1.1(\mathrm{~S})$ & $1.1(\mathrm{~S})$ \\
\hline $\mathbf{T} 25$ & $\mathrm{R}$ & $\mathrm{R}$ & $1.9(\mathrm{~S})$ & $1.9(\mathrm{~S})$ & $\mathrm{R}$ & $\mathrm{R}$ & $0.5(\mathrm{R})$ & $0.5(\mathrm{R})$ & $1.8(\mathrm{~S})$ & $1.8(\mathrm{~S})$ & $2.8(\mathrm{~S})$ & $2.8(\mathrm{~S})$ \\
\hline T26 & $\mathrm{R}$ & $\mathrm{R}$ & $\mathrm{R}$ & $\mathrm{R}$ & $\mathrm{R}$ & $\mathrm{R}$ & $1.7(\mathrm{~S})$ & $1.7(\mathrm{~S})$ & $\mathrm{R}$ & $\mathrm{R}$ & $1.5(\mathrm{~S})$ & $1.5(\mathrm{~S})$ \\
\hline $\mathbf{T} 27$ & $\mathrm{R}$ & $\mathrm{R}$ & $\mathrm{R}$ & $2.8(\mathrm{~S})$ & $\mathrm{R}$ & $\mathrm{R}$ & $\mathrm{R}$ & $\mathrm{R}$ & $\mathrm{R}$ & $\mathrm{R}$ & $\mathrm{R}$ & $1.9(\mathrm{~S})$ \\
\hline T28 & $\mathrm{R}$ & $\mathrm{R}$ & $\mathrm{R}$ & $3.8(\mathrm{~S})$ & $\mathrm{R}$ & $\mathrm{R}$ & $0.1(\mathrm{R})$ & $0.1(\mathrm{R})$ & $\mathrm{R}$ & $\mathrm{R}$ & $\mathrm{R}$ & $3.9(\mathrm{~S})$ \\
\hline T29 & $\mathrm{R}$ & $\mathrm{R}$ & $\mathrm{R}$ & $2,(\mathrm{~S})$ & $\mathrm{R}$ & $\mathrm{R}$ & $1.6(\mathrm{~S})$ & $1.6(\mathrm{~S})$ & $\mathrm{R}$ & $\mathrm{R}$ & $\mathrm{R}$ & $0.5(\mathrm{~S})$ \\
\hline T30 & $\mathrm{R}$ & $\mathrm{R}$ & $\mathrm{R}$ & $3.2(\mathrm{~S})$ & $\mathrm{R}$ & $1(\mathrm{~S})$ & $1(\mathrm{~S})$ & $1(\mathrm{~S})$ & $\mathrm{R}$ & $\mathrm{R}$ & $\mathrm{R}$ & $2.6(\mathrm{~S})$ \\
\hline
\end{tabular}




\begin{tabular}{|c|c|c|c|c|c|c|c|c|c|c|c|c|}
\hline & \multicolumn{4}{|c|}{$\mathrm{Cd}^{+2}$} & \multicolumn{4}{|c|}{$\mathrm{Cu}^{+2}$} & \multicolumn{4}{|c|}{$\mathbf{P b}^{+2}$} \\
\hline $\mathbf{T 1}$ & $\mathrm{R}$ & $\mathrm{R}$ & $\mathrm{R}$ & $\mathrm{R}$ & $\mathrm{R}$ & $\mathrm{R}$ & $\mathrm{R}$ & $\mathrm{R}$ & $\mathrm{R}$ & $\mathrm{R}$ & $\mathrm{R}$ & $\mathrm{R}$ \\
\hline $\mathbf{T} 2$ & $\mathrm{R}$ & $\mathrm{R}$ & $\mathrm{R}$ & $\mathrm{R}$ & $\mathrm{R}$ & $\mathrm{R}$ & $\mathrm{R}$ & $\mathrm{R}$ & $\mathrm{R}$ & $\mathrm{R}$ & $\mathrm{R}$ & $\mathrm{R}$ \\
\hline T3 & $\mathrm{R}$ & $\mathrm{R}$ & $\mathrm{R}$ & $\mathrm{R}$ & $\mathrm{R}$ & $\mathrm{R}$ & $\mathrm{R}$ & $\mathrm{R}$ & $\mathrm{R}$ & $\mathrm{R}$ & $\mathrm{R}$ & $\mathrm{R}$ \\
\hline T4 & $\mathrm{R}$ & $\mathrm{R}$ & $\mathrm{R}$ & $\mathrm{R}$ & $\mathrm{R}$ & $\mathrm{R}$ & $\mathrm{R}$ & $\mathrm{R}$ & $\mathrm{R}$ & $\mathrm{R}$ & $\mathrm{R}$ & $\mathrm{R}$ \\
\hline T5 & $\mathrm{R}$ & $\mathrm{R}$ & $\mathrm{R}$ & $\mathrm{R}$ & $\mathrm{R}$ & $\mathrm{R}$ & $\mathrm{R}$ & $\mathrm{R}$ & $\mathrm{R}$ & $\mathrm{R}$ & $\mathrm{R}$ & $\mathrm{R}$ \\
\hline T6 & $\mathrm{R}$ & $\mathrm{R}$ & $\mathrm{R}$ & $\mathrm{R}$ & $\mathrm{R}$ & $\mathrm{R}$ & $\mathrm{R}$ & $\mathrm{R}$ & $\mathrm{R}$ & $\mathrm{R}$ & $\mathrm{R}$ & $\mathrm{R}$ \\
\hline T7 & $\mathrm{R}$ & $\mathrm{R}$ & $\mathrm{R}$ & $\mathrm{R}$ & $\mathrm{R}$ & $\mathrm{R}$ & $\mathrm{R}$ & $\mathrm{R}$ & $\mathrm{R}$ & $\mathrm{R}$ & $\mathrm{R}$ & $\mathrm{R}$ \\
\hline T8 & $\mathrm{R}$ & $\mathrm{R}$ & $\mathrm{R}$ & $\mathrm{R}$ & $\mathrm{R}$ & $\mathrm{R}$ & $\mathrm{R}$ & $\mathrm{R}$ & $\mathrm{R}$ & $\mathrm{R}$ & $\mathrm{R}$ & $\mathrm{R}$ \\
\hline T9 & $\mathrm{R}$ & $\mathrm{R}$ & $\mathrm{R}$ & $0.9(\mathrm{~S})$ & $\mathrm{R}$ & $\mathrm{R}$ & $\mathrm{R}$ & $\mathrm{R}$ & $\mathrm{R}$ & $\mathrm{R}$ & $\mathrm{R}$ & $\mathrm{R}$ \\
\hline T10 & $\mathrm{R}$ & $\mathrm{R}$ & $\mathrm{R}$ & $\mathrm{R}$ & $\mathrm{R}$ & $\mathrm{R}$ & $\mathrm{R}$ & $\mathrm{R}$ & $\mathrm{R}$ & $\mathrm{R}$ & $\mathrm{R}$ & $\mathrm{R}$ \\
\hline T11 & $\mathrm{R}$ & $\mathrm{R}$ & $1(\mathrm{~S})$ & $1(\mathrm{~S})$ & $\mathrm{R}$ & $\mathrm{R}$ & $\mathrm{R}$ & $2(\mathrm{~S})$ & $\mathrm{R}$ & $\mathrm{R}$ & $\mathrm{R}$ & $\mathrm{R}$ \\
\hline T12 & $\mathrm{R}$ & $\mathrm{R}$ & $\mathrm{R}$ & $\mathrm{R}$ & $\mathrm{R}$ & $\mathrm{R}$ & $\mathrm{R}$ & $1.8(\mathrm{~S})$ & $\mathrm{R}$ & $\mathrm{R}$ & $\mathrm{R}$ & $2,(\mathrm{~S})$ \\
\hline T13 & $\mathrm{R}$ & $\mathrm{R}$ & $\mathrm{R}$ & $\mathrm{R}$ & $\mathrm{R}$ & $\mathrm{R}$ & $\mathrm{R}$ & $2.2(\mathrm{~S})$ & $\mathrm{R}$ & $\mathrm{R}$ & $\mathrm{R}$ & $3.2(\mathrm{~S})$ \\
\hline T14 & $3(\mathrm{~S})$ & $3.2(\mathrm{~S})$ & $3.2(\mathrm{~S})$ & $3.2(\mathrm{~S})$ & $3,(\mathrm{~S})$ & $3.9(\mathrm{~S})$ & $3.9(\mathrm{~S})$ & $3.9(\mathrm{~S})$ & $\mathrm{R}$ & $\mathrm{R}$ & $\mathrm{R}$ & $\mathrm{R}$ \\
\hline T15 & $\mathrm{R}$ & $\mathrm{R}$ & $\mathrm{R}$ & $\mathrm{R}$ & $\mathrm{R}$ & $0.9(\mathrm{~S})$ & $2,(\mathrm{~S})$ & $2,(\mathrm{~S})$ & $\mathrm{R}$ & $\mathrm{R}$ & $\mathrm{R}$ & $\mathrm{R}$ \\
\hline T16 & $\mathrm{R}$ & $\mathrm{R}$ & $\mathrm{R}$ & $0.7(\mathrm{~S})$ & $\mathrm{R}$ & $1(\mathrm{~S})$ & $1,(\mathrm{~S})$ & $1.3(\mathrm{~S})$ & $\mathrm{R}$ & $\mathrm{R}$ & $\mathrm{R}$ & $\mathrm{R}$ \\
\hline T17 & $\mathrm{R}$ & $\mathrm{R}$ & $\mathrm{R}$ & $\mathrm{R}$ & $1.3(\mathrm{~S})$ & $1.3(\mathrm{~S})$ & $2.3(\mathrm{~S})$ & $2.3(\mathrm{~S})$ & $\mathrm{R}$ & $\mathrm{R}$ & $\mathrm{R}$ & $\mathrm{R}$ \\
\hline T18 & $\mathrm{R}$ & $\mathrm{R}$ & $\mathrm{R}$ & $\mathrm{R}$ & $1.4(\mathrm{~S})$ & $1.4(\mathrm{~S})$ & $1.6(\mathrm{~S})$ & $1.6(\mathrm{~S})$ & $\mathrm{R}$ & $\mathrm{R}$ & $\mathrm{R}$ & $\mathrm{R}$ \\
\hline T19 & $\mathrm{R}$ & $\mathrm{R}$ & $1(\mathrm{~S})$ & $1(\mathrm{~S})$ & $1(\mathrm{~S})$ & $1(\mathrm{~S})$ & $1(\mathrm{~S})$ & $1(\mathrm{~S})$ & $\mathrm{R}$ & $\mathrm{R}$ & $\mathrm{R}$ & $\mathrm{R}$ \\
\hline T20 & $\mathrm{R}$ & $0.8(\mathrm{~S})$ & $1(\mathrm{~S})$ & $1.6(\mathrm{~S})$ & $\mathrm{R}$ & $0.1(\mathrm{R})$ & $1.2(\mathrm{~S})$ & $1.9(\mathrm{~S})$ & $\mathrm{R}$ & $1,(\mathrm{~S})$ & $1.9(\mathrm{~S})$ & $2.9(\mathrm{~S})$ \\
\hline T21 & $1.4(\mathrm{~S})$ & $1.9(\mathrm{~S})$ & $1.9(\mathrm{~S})$ & $1.9(\mathrm{~S})$ & $2.6(\mathrm{~S})$ & $3.6(\mathrm{~S})$ & $3.6(\mathrm{~S})$ & $3.6(\mathrm{~S})$ & $\mathrm{R}$ & $\mathrm{R}$ & $0.5(\mathrm{~S})$ & $1.3(\mathrm{~S})$ \\
\hline T22 & $\mathrm{R}$ & $\mathrm{R}$ & $\mathrm{R}$ & $1,(\mathrm{~S})$ & $2.7(\mathrm{~S})$ & $3.7(\mathrm{~S})$ & $4(\mathrm{~S})$ & $4(\mathrm{~S})$ & $\mathrm{R}$ & $\mathrm{R}$ & $\mathrm{R}$ & $0.9(\mathrm{~S})$ \\
\hline T23 & $0.8(\mathrm{~S})$ & $0.8(\mathrm{~S})$ & $1.8(\mathrm{~S})$ & $1.9(\mathrm{~S})$ & $2.3(\mathrm{~S})$ & $2.6(\mathrm{~S})$ & $2.8(\mathrm{~S})$ & $2.8(\mathrm{~S})$ & $\mathrm{R}$ & $\mathrm{R}$ & $\mathrm{R}$ & $\mathrm{R}$ \\
\hline T24 & $2.5(\mathrm{~S})$ & $3.9(\mathrm{~S})$ & $3.9(\mathrm{~S})$ & $3.9(\mathrm{~S})$ & $2.8(\mathrm{~S})$ & $3.8(\mathrm{~S})$ & $3.8(\mathrm{~S})$ & $3.8(\mathrm{~S})$ & $\mathrm{R}$ & $\mathrm{R}$ & $\mathrm{R}$ & $\mathrm{R}$ \\
\hline T25 & $2(\mathrm{~S})$ & $2(\mathrm{~S})$ & $2,(\mathrm{~S})$ & $2,(\mathrm{~S})$ & $4.9(\mathrm{~S})$ & $4.9(\mathrm{~S})$ & $4.9(\mathrm{~S})$ & $4.9(\mathrm{~S})$ & $\mathrm{R}$ & $\mathrm{R}$ & $\mathrm{R}$ & $\mathrm{R}$ \\
\hline T26 & $\mathrm{R}$ & $\mathrm{R}$ & $0.8(\mathrm{~S})$ & $0.8(\mathrm{~S})$ & $\mathrm{R}$ & $\mathrm{R}$ & $0.1(\mathrm{R})$ & $0.1(\mathrm{R})$ & $\mathrm{R}$ & $\mathrm{R}$ & $1,(\mathrm{~S})$ & $1,(\mathrm{~S})$ \\
\hline T27 & $\mathrm{R}$ & $\mathrm{R}$ & $1.9(\mathrm{~S})$ & $1.9(\mathrm{~S})$ & $\mathrm{R}$ & $\mathrm{R}$ & $3.6(\mathrm{~S})$ & $3.6(\mathrm{~S})$ & $\mathrm{R}$ & $\mathrm{R}$ & $\mathrm{R}$ & $\mathrm{R}$ \\
\hline T28 & $\mathrm{R}$ & $\mathrm{R}$ & $\mathrm{R}$ & $\mathrm{R}$ & $\mathrm{R}$ & $\mathrm{R}$ & $3.7(\mathrm{~S})$ & $3.7(\mathrm{~S})$ & $\mathrm{R}$ & $\mathrm{R}$ & $\mathrm{R}$ & $\mathrm{R}$ \\
\hline T29 & $\mathrm{R}$ & $\mathrm{R}$ & $\mathrm{R}$ & $1.9(\mathrm{~S})$ & $\mathrm{R}$ & $\mathrm{R}$ & $\mathrm{R}$ & $2.8(\mathrm{~S})$ & $\mathrm{R}$ & $\mathrm{R}$ & $\mathrm{R}$ & $\mathrm{R}$ \\
\hline T30 & $\mathrm{R}$ & $\mathrm{R}$ & $\mathrm{R}$ & $3.9(\mathrm{~S})$ & $\mathrm{R}$ & $\mathrm{R}$ & $\mathrm{R}$ & $3.8(\mathrm{~S})$ & $\mathrm{R}$ & $1.3(\mathrm{~S})$ & $1(\mathrm{~S})$ & $1(\mathrm{~S})$ \\
\hline
\end{tabular}

ICs: Isolate codes. R: Resistance. S: sensitive. *: Inhibition zone dimension

Results in Figures 4 and 5 revealed that the lag phase growth started in the $1^{\text {st }}$ day of bacterial isolates (T1, T2, T3, T4 and T5) and in the $2^{\text {nd }}$ day for the isolates (T6, T7, T8, T10 and T18). Four recognizable phases are seen when the increase in cell number was determined in relation to time by lag phase, log phase, stationary phase and decline phase (Priyadharshini and Kumar, 2016).

The lag phase continuously in the growth for the $3^{\text {rd }}$ day and the highest OD $(0.61 \mathrm{~nm})$ was recorded with isolates T10 and T18. Regarding to the log phase, the three isolates coded T1, T3 and T4 registered the highest values $(0.41,0.40$ and $0.46 \mathrm{~nm}$ ) respectively. The stationary phase was observed in the $5^{\text {th }}$ day and the high value was recorded for T3 isolate $(0.42 \mathrm{~nm})$ and T6 isolate $(0.41 \mathrm{~nm})$. From the $6^{\text {th }}$ day all the tested bacterial isolates started in the decline phase. The obtained data indicated that the selected bacterial isolates (T1, T3 and T4) were continuously to the growth from the $1^{\text {st }}$ day until the $5^{\text {th }}$ day and the optimum growth period was registered in the $4^{\text {th }}$ day. These 
results considering that the selected bacterial isolates (T1, T3 and T4) are promising bacteria for up taking the heavy metal ions from EIWW.

Effect of EIWW toxicity on the abilities of the selected bacterial isolates to produce IAA was studied. Results in Table 3 (illustrated by Fig. 6) showed that the selected bacterial isolates were varied in their production of IAA affected by EIWW.

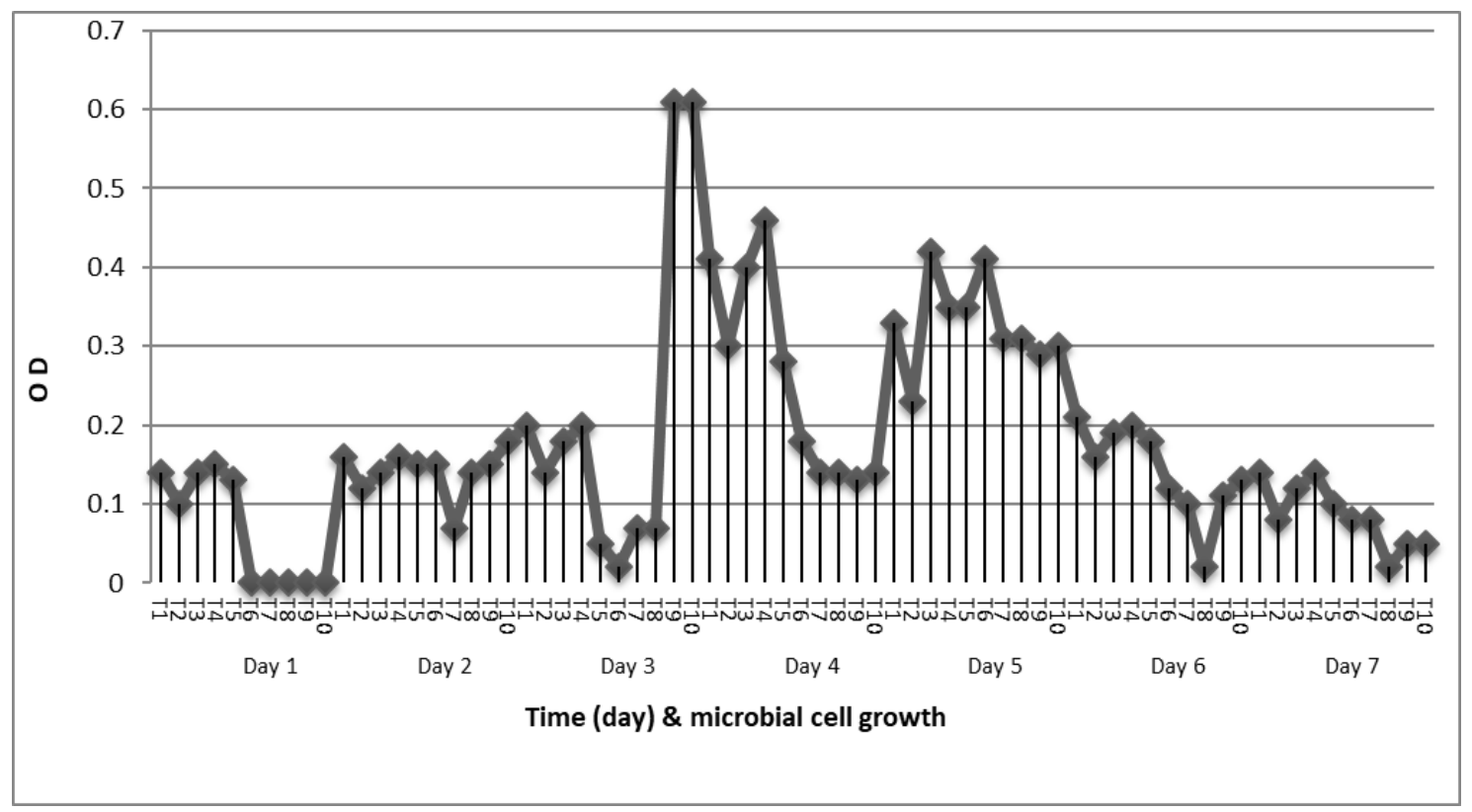

Figure 4. Optical density $(\lambda=620 \mathrm{~nm})$ of ten selected bacterial isolates $(T 1, T 2, T 3, T 4, T 5, T 6$, T7, T8, T10 and T18) as affected by growth periods

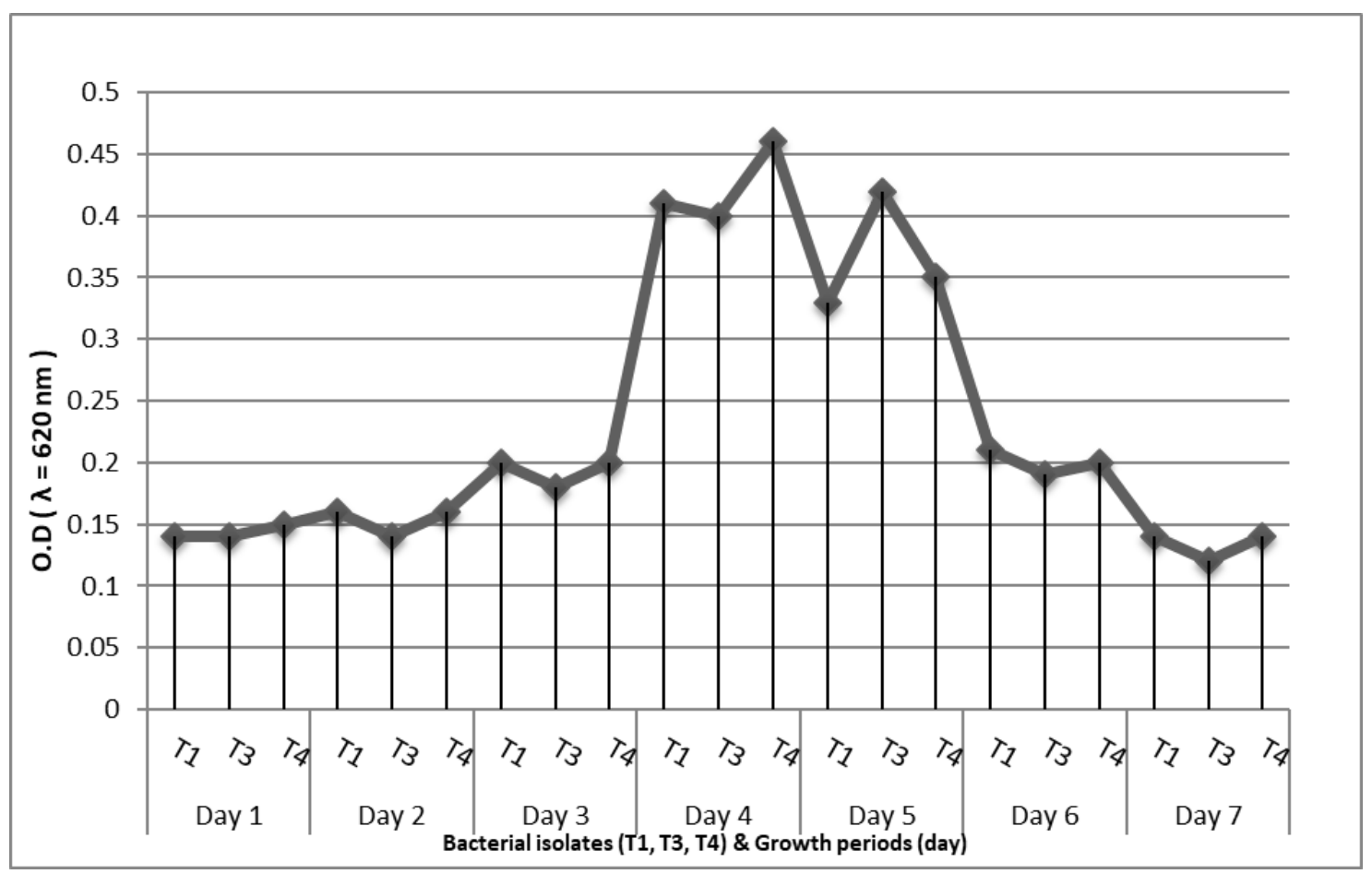

Figure 5. Optical density $(\lambda=620 \mathrm{~nm})$ of three selected bacterial isolates (T1, T3, and T4) as affected by growth periods 


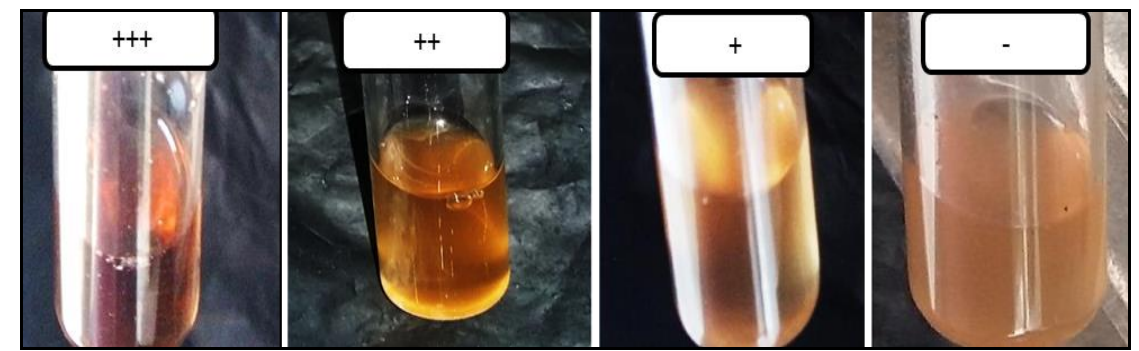

Figure 6. Photos shows the IAA visual reaction degrees of a bacterial isolate for IAA production, [high $(+++)$, moderate $(++)$, low $(+)$, no reaction $(-)$ ]

Table 3. Degree of color changes of bacterial isolates (T1, T2, T3, T4, T5, T6, T7, T8, T10 and T18) to producing IAA on NBM containing SIWW, and L-tryptophan $(0.1 \%, \mathrm{v} / \mathrm{w})$

\begin{tabular}{c|c}
\hline Bacterial isolates code & IAA visual reaction degrees \\
\hline $\mathrm{T} 1$ & Moderate \\
$\mathrm{T} 2$ & High \\
$\mathrm{T} 3$ & Moderate \\
$\mathrm{T} 4$ & Moderate \\
$\mathrm{T} 5$ & Moderate \\
$\mathrm{T} 6$ & Moderate \\
$\mathrm{T} 7$ & Low \\
$\mathrm{T} 8$ & Low \\
$\mathrm{T} 10$ & Low \\
$\mathrm{T} 18$ & Low \\
\hline
\end{tabular}

These results are harmony with that reported by Özdal et al. (2016) who reported that the production of IAA dependence on the Bacillus spp. isolates and fermentation time. Isolate (T2) gave the highest degree of color change that evidence on its high ability for the consumption of L-tryptophan and IAA production, while, the T1, T3, T4, T5 and T6 isolates gave the moderate degree of color change. The lowest degree for color change was noticed by T7, T8, T10 and T18 isolates. From these results three bacterial isolates coded T1, T3 and T4 were selected and subjected to biological and molecular identification.

\section{Determination of antibiosis activities of the ten bacterial isolates}

Data presented in Table 4 and Figure 7 revealed that the all tested bacterial isolates gave antibiosis reaction against $E$. coli when growing on NAM. Similar results were obtained by Yilmaz et al. (2006), who mentioned that B. cereus has inhibitory affect both against Gram-positive and Gram-negative bacteria. Negative reaction was recorded with T2 and T6 isolates against $F$. solani and S. relfsii. The rest of bacterial isolates, T1, T3, T4, T5, T7, T8, T10 and T18 have positive reaction against the three tested pathogens ( $F$. solani, $S$. relfsii and E. coli).

These results are in harmony with that of Kim et al. (2015), who showed that the Bacillus spp. had broad-spectrum antifungal activity against $F$. solani and $F$. oxysporum. Results of Ghai et al. (2007) also supported this study, as they recorded that the more strains of Bacillus spp. had antagonistic activities against some fungal 
pathogens, e.g. Clerotium rolfsii, Fusarium oxysporum and Rhizoctonia solani. Based on these results it has been observed that, three isolates coded T1, T3 and T4 were selected and subjected to biological and molecular identification.

Table 4. Antibiosis activities of bacterial isolates (T1, T2, T3, T4, T5, T6, T7, T8, T10 and T18) against F. solani, S. relfsii and E. coli

\begin{tabular}{c|c|c|c}
\hline \multirow{2}{*}{ Bacterial isolates code } & \multicolumn{3}{|c}{ Antibiosis reaction } \\
\cline { 2 - 4 } & $\boldsymbol{F .}$ solani & S. rolfsii & E. coli \\
\hline T1 & + & + & + \\
T2 & - & - & + \\
T3 & + & + & + \\
T4 & + & + & + \\
T5 & + & + & + \\
T6 & - & + & + \\
T7 & + & + & + \\
T8 & + & + & + \\
T10 & + & + & + \\
T18 & + &
\end{tabular}

+: Antibiosis, -: Non antibiosis

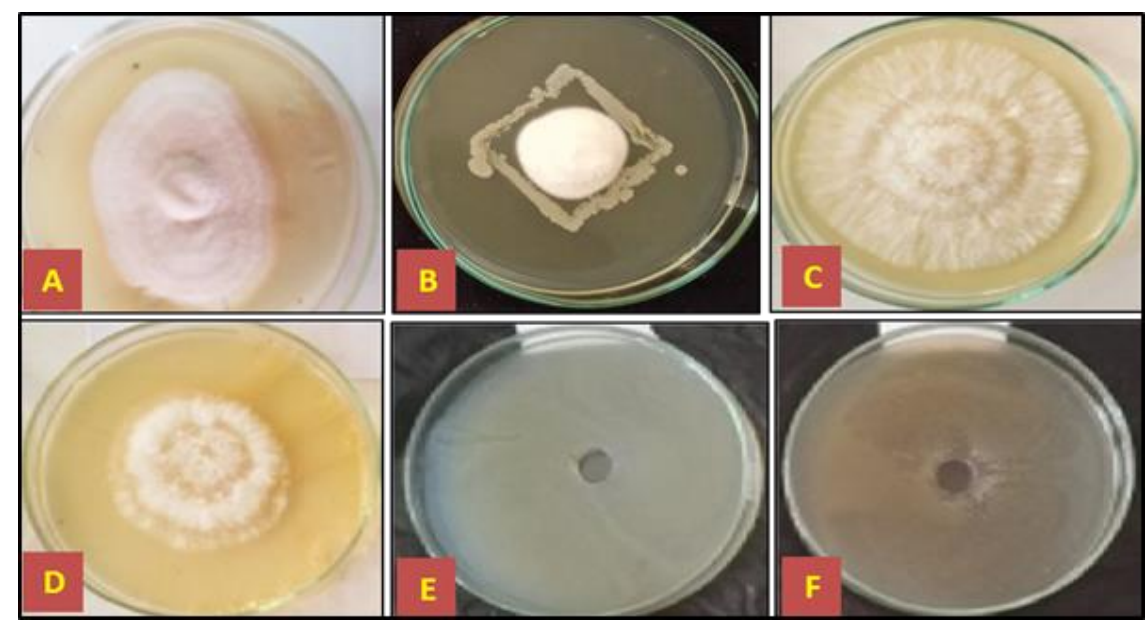

Figure 7. Antibiosis activities of abacterial isolate against $F$. solani $(A), S$. rolfsii $(C)$ and $E$. coli $(E)$ compared to the growth alone to every one $(B, D$ and $F)$, respectively

\section{Biological identification of the selected bacterial isolates}

The bacterial isolates which were selected based on their growth curve; IAA reaction (color change) and antibiosis effect were identified according to (Juni 1986) mentioned in Bergey's Manual of Systematic Bacteriology $(1986,2012)$ and Barrow and Felltham (1993).

Morphological, biochemical characterization and utilization of carbohydrates as carbon sources via the bacterial isolates which coded with T1, T3 and T4 are presented in Table 5. On NAM, all 48 h-old cultures of tested isolates were positive to Gram stain, motile, rod shaped with white colony for T3, T4 isolates and yellowish colony for T1 
isolate. Furthermore, all bacterial isolates were positive effect on both catalase and Indole tests. The coded isolates T1 and T3 were negative with oxidase, Methyl-red and citrate tests. All isolates utilized sucrose and lactose as carbon sources, while, T1 failed to utilize glucose, maltose and xylose. From the obtained data and classifying bacterial isolates in accordance to Claus and Berkeley (1986) that identified the coded (T1, T3 and T4) as Bacillus spp., Bacillus cereus and Bacillus altitudinis, respectively.

Table 5. Morphological and biochemical characterization, utilization of carbohydrate test of Bacterial isolates (Claus and Berkeley, 1986; Barrow and Felltham, 1993)

\begin{tabular}{|c|c|c|c|}
\hline \multirow{2}{*}{ Characters } & \multicolumn{3}{|c|}{ Bacterial isolates } \\
\hline & T1 & T3 & T4 \\
\hline \multicolumn{4}{|c|}{ Morphological characteristics } \\
\hline Colony color on agar & Yellowish & White & White \\
\hline Gram stain & Positive & Positive & Positive \\
\hline Cell shape & Rod & Rod & Rod \\
\hline Motility & Motile & Motile & Motile \\
\hline \multicolumn{4}{|c|}{ Biochemical test results } \\
\hline Oxidase & + & + & + \\
\hline Catalase & + & + & + \\
\hline Indole & + & + & + \\
\hline Methyl-Red & - & + & + \\
\hline Citrate & - & + & + \\
\hline \multicolumn{4}{|c|}{ Utilization of carbohydrate } \\
\hline Glucose & - & + & + \\
\hline Sucrose & + & + & + \\
\hline Maltose & - & + & + \\
\hline Xylose & - & + & + \\
\hline Lactose & + & + & + \\
\hline Nomenclatures & Bacillus spp. & Bacillus cereus & Bacillus altitudinis \\
\hline
\end{tabular}

+: Positive, -: Negative

\section{Molecular identification of the selected bacterial isolates}

Biological identification of the three bacterial isolates alone was not completely enough, and these tests consume a lot of time and chemicals. Due to the advanced technology such as 16SrRNA gene, primers had been developed by investigators to target specifically the $16 \mathrm{~S}$ rRNA sequence of the bacteria. In this search, the three bacterial isolates obtained from EIWW samples were also identified using primers targeting their 16S rRNA sequence (Jeffrey, 2008). The nucleotide sequences of $16 \mathrm{~S}$ rRNA gene were partially determined using the DNA template of the three bacterial isolates (T1, T3, and T4). Results showed that partial sequences of 985, 997 and $983 \mathrm{nts}$ were obtained for the three isolates, respectively. These sequences were compared with four universal bacterial isolates as mentioned in Table 5. These bacteria were classified as Bacillus sp. SMMAA-1, Bacillus cereus SMMAA-3 and Bacillus altitudinis SMMAA-4 and documented in GenBank under the accession numbers of LC472522, LC472523 and LC472524, respectively. Results in Table 6 showed that the percent 
identities between the three bacterial strains and those similar strains recorded in GenBank ranged from $84.85 \%$ to $100.00 \%$. Phylogenetic trees of the three bacterial strains compared to that similar strain in GenBank confirmed the biological identification of these strains as illustrated in Figure 8.

Table 6. Sequences producing significant alignments of the three bacterial strains compared to those similar strains in GenBank with E-value (0.0)

\begin{tabular}{|c|c|c|c|}
\hline Description & $\begin{array}{c}\text { Query cover } \\
(\%)\end{array}$ & $\begin{array}{c}\text { Identities } \\
(\%)\end{array}$ & Accession \\
\hline \multicolumn{4}{|l|}{ T1 isolate (LC472522) } \\
\hline Bacillus altitudinis strain P-10 chromosome, complete genome & 91 & 84.97 & СР024204.1 \\
\hline Bacillus aerophilus strain 232 chromosome, complete genome & 91 & 84.85 & СР026008.1 \\
\hline Bacillus altitudinis strain SGAir0031 chromosome, complete genome & 91 & 84.85 & СР022319.2 \\
\hline Bacillus cellulasensis strain GLB197, complete genome & 91 & 84.85 & СР018574.1 \\
\hline \multicolumn{4}{|l|}{ T3 isolate (LC472523) } \\
\hline Bacillus cereus strain ATCC 14579 16S ribosomal RNA (rrnA), partial sequence & 98 & 100.00 & NR_074540.1 \\
\hline Bacillus thuringiensis $16 \mathrm{~S}$ rRNA gene and $16 \mathrm{~S}-23 \mathrm{~S}$ IGS, strain SBS-BT6 & 98 & 99.73 & AM779002.1 \\
\hline Bacillus mycoides $16 \mathrm{~S}$ rRNA gene, strain MWS5303-1-4 & 98 & 99.46 & Z84591.1 \\
\hline Bacillus thuringiensis $16 \mathrm{~S}$ rRNA gene and 16S-23S IGS, strain SBS-BT3 & 98 & 99.46 & AM778999.1 \\
\hline \multicolumn{4}{|l|}{ T4 isolate (LC472524) } \\
\hline Bacillus altitudinis strain $\mathrm{P}-10$ chromosome, complete genome & 99 & 99.08 & СР024204.1 \\
\hline Bacillus cellulasensis strain GLB197, complete genome & 99 & 98.98 & СР018574.1 \\
\hline Bacillus aerophilus strain 232 chromosome, complete genome & 99 & 99.08 & СР026008.1 \\
\hline Bacillus altitudinis strain SGAir0031 chromosome, complete genome & 99 & 99.08 & СР022319.2 \\
\hline
\end{tabular}

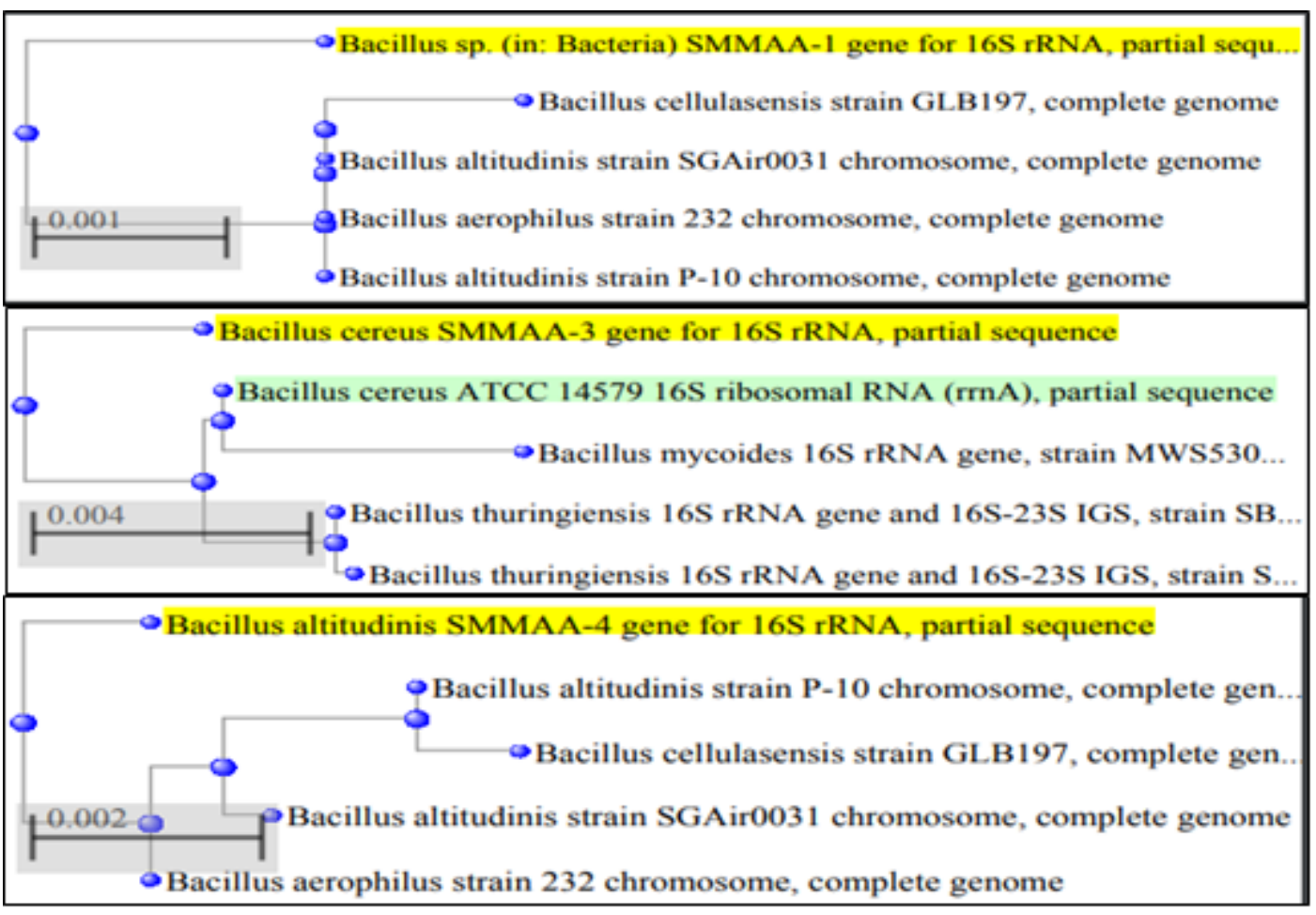

Figure 8. Phylogenetic trees of the three bacterial strains compared to those similar strains in GenBank 
Role of selected bacterial isolates (Bacillus spp., B. cereus and B. altitudinis) on the biosorption of six heavy metals $\left(\mathrm{Zn}^{+2}, \mathrm{Fe}^{+2}, \mathrm{Co}^{+2}, \mathrm{Cd}^{+2}, \mathrm{Cu}^{+2}\right.$ and $\left.\mathrm{Pb}^{+2}\right)$ from industrial wastewater (IWW)

Biosorption efficiency of heavy metals from SIWW by Bacillus spp., B. cereus and B. altitudinis is depicted in Table 7 and Figure 9. Data showed that the initial values of six heavy metals (ppm) were founded by diversity in IWW and wide ranged from $1.4 \mathrm{ppm}$ to $6 \mathrm{ppm}$. The maximum conc. was found with $\mathrm{Zn}^{+2}(6 \mathrm{ppm})$ while, the minimum conc. was found with $\mathrm{Co}^{+2}(1.4 \mathrm{ppm})$. The values of final metal conc. of heavy metals in SIWW were reduced as result of biosorption occurred by bacteria and ranged from $0.109 \mathrm{ppm}$ to $0.409 \mathrm{ppm}$ compared to the initial metal conc. $(2.450 \mathrm{ppm})$. The ability of bacterial isolates tested (Bacillus spp., B. cereus and B. altitudinis) for biosorption of the six heavy metals were differed among them.

Table 7. Initial and residual values of heavy metals (ppm) in IWW as affected by SIWW inoculated with the selected bacteria (Bacillus spp., B. cereus and B. altitudinis)

\begin{tabular}{|c|c|c|c|c|c|}
\hline \multirow[b]{2}{*}{ Heavy metals } & \multirow{2}{*}{$\begin{array}{l}\text { Initial metal } \\
\text { conc. (ppm) }\end{array}$} & \multicolumn{3}{|c|}{ Residual values of heavy metals (ppm) } & \multirow[b]{2}{*}{ Mean } \\
\hline & & $\begin{array}{c}\text { SIWW + Bacill } \\
\text { us spp. }\end{array}$ & $\begin{array}{l}\text { SIWW + B. } \\
\text { cereus }\end{array}$ & $\begin{array}{c}\text { SIWW + B. } \\
\text { altitudinis }\end{array}$ & \\
\hline $\mathrm{Zn}$ & 6.000 & 0.551 & 0.016 & 0.490 & 0.352 \\
\hline $\mathrm{Fe}$ & 2.100 & 1.782 & 0.552 & 1.782 & 1.372 \\
\hline Co & 1.400 & 0.002 & 0.004 & 0.008 & 0.004 \\
\hline $\mathrm{Cd}$ & 1.800 & 0.017 & 0.016 & 0.019 & 0.017 \\
\hline $\mathrm{Cu}$ & 1.500 & 0.017 & 0.004 & 0.014 & 0.011 \\
\hline $\mathrm{Pb}$ & 1.900 & 0.087 & 0.063 & 0.097 & 0.082 \\
\hline Mean & 2.450 & 0.409 & 0.109 & 0.401 & \\
\hline
\end{tabular}

IWW = Industrial Wastewater, SIWW = Sterile Industrial Wastewater

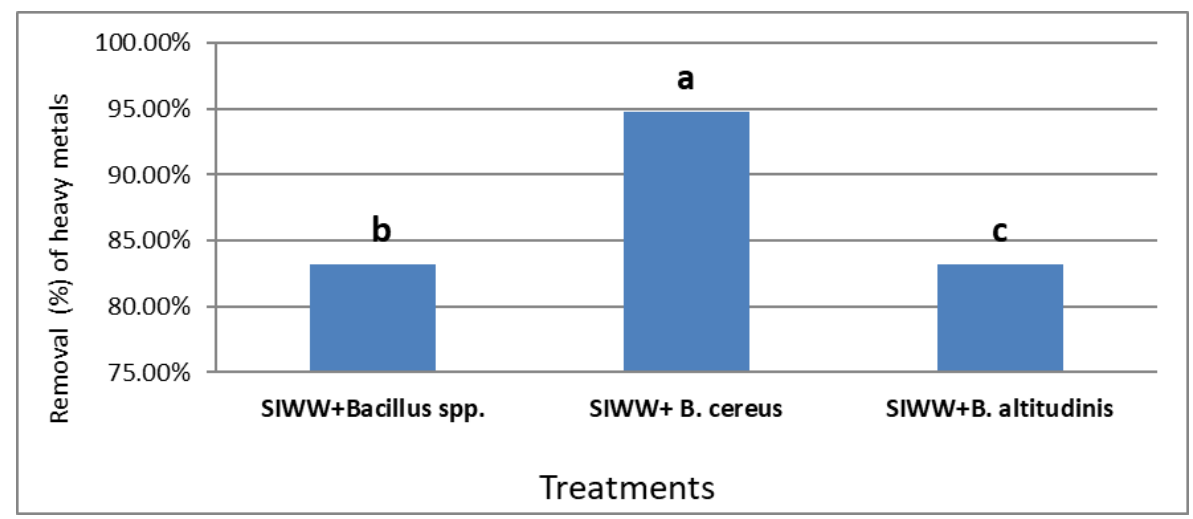

Figure 9. Average of the mean values (A) of the heavy metals removal \% of IWW as affected by SIWW inoculated with the selected bacteria (Bacillus spp, B. cereus and B. altitudinis). Values having the same alphabetical letter within each column are not significantly different at the 0.05 level according to (Duncan multiple range test)

Data exhibited that B. cereus was more effected than B. altitudinis and Bacillus spp. for biosorption final metal conc. $(0.109,0.401$ and $0.409 \mathrm{ppm})$ respectively. Also, the data indicated that $\left(\mathrm{Co}^{+2}\right)$ ion was more biosorption by the three bacterial isolates and gave the 
little values compared to $\left(\mathrm{Fe}^{+2}\right)$ which gave the highest values in IWW. The ions $\left(\mathrm{Co}^{+2}\right.$ and $\mathrm{Cu}^{+2}$ ) recorded the highest biosorption by the three bacterial isolates followed by the $\left(\mathrm{Zn}^{+2}, \mathrm{~Pb}^{+2}\right.$ and $\left.\mathrm{Cd}^{+2}\right)$ but the lowest biosorption recorded with $\mathrm{Fe}^{+2}$ metal.

From the obtained result data revealed that the all bacterial isolates play an important role in detoxification of heavy metals founded in the IWW of Abu-kerqas sugar factoryEl-Minia, Egypt. The all studied bacteria were more effective for the biosorption of the heavy metal contents in SIWW. $\mathrm{Co}^{+2}$ ion was more absorbed by Bacillus spp. (0.002 ppm) followed by B. cereus $(0.004 \mathrm{ppm})$ and B. altitudinis $(0.008 \mathrm{ppm})$.

The results presented in Table 8 and Figure 9 show the biosorption ability of $B$. cereus is significantly effective for removal efficiency percentage of six heavy metals $\left(\mathrm{Zn}^{+2}, \mathrm{Fe}^{+2}, \mathrm{Co}^{+2}, \mathrm{Cd}^{+2}, \mathrm{Cu}^{+2}\right.$ and $\left.\mathrm{Pb}^{+2}\right)(94.77 \%)$ from IWW. However, the removal efficiency $\%$ of it is heavy metals using Bacillus spp. and B. altitudinis recorded $83.19 \%$ and $83.21 \%$ with insignificant difference between them. This indicted that $B$. cereus has a higher capability of biosorption potentiality of heavy metals compared to the others. Similar results are recorded by Huang et al. (2013).

Regarding to the effects of the different heavy metals tested for the removal efficiency \%, the results in Table 8 and Figure 10 show significant effects. Available data revealed that higher removal efficiencies of $99.66 \%$ for $\mathrm{Co}^{+2}, 99.22 \%$ for $\mathrm{Cu}^{+2}$ and $99.03 \%$ for $\mathrm{Cd}^{+2}$ and lower removal efficiencies $34.66 \%$ for $\mathrm{Fe}^{+2}$ were recorded as Mullen et al. (1989).

Table 8. Removal efficiency \% of heavy metals from IWWas affected by SIWW inoculated with the selected bacteria (Bacillus spp., B. cereus and B. altitudinis)

\begin{tabular}{|c|c|c|c|c|c|c|c|}
\hline \multirow{2}{*}{ Treatments } & \multicolumn{7}{|c|}{ Removal efficiency \% of heavy metals } \\
\hline & $\mathbf{Z n}^{+2}$ & $\mathrm{Fe}^{+2}$ & $\mathrm{Co}^{+2}$ & $\mathrm{Cd}^{+2}$ & $\mathrm{Cu}^{+2}$ & $\mathbf{P b}^{+2}$ & Mean of A \\
\hline Bacillus spp. + SIWW & $90.83 \mathrm{~d}$ & $15.14 \mathrm{f}$ & $99.86 \mathrm{a}$ & $99.06 \mathrm{a}$ & $98.87 \mathrm{a}$ & $95.42 \mathrm{bc}$ & $83.19 \mathrm{~b}$ \\
\hline B. cereus + SIWW & $99.73 \mathrm{a}$ & $73.71 \mathrm{e}$ & $99.71 \mathrm{a}$ & $99.11 \mathrm{a}$ & $99.73 \mathrm{a}$ & $96.68 \mathrm{~b}$ & $94.77 \mathrm{a}$ \\
\hline B. altitudinis + SIWW & $91.83 \mathrm{c}$ & $15.14 \mathrm{f}$ & $99.42 \mathrm{a}$ & $98.94 \mathrm{a}$ & $99.06 \mathrm{a}$ & $94.89 \mathrm{bc}$ & $83.21 \mathrm{~b}$ \\
\hline Mean of B & $94.13 \mathrm{~b}$ & $34.66 \mathrm{c}$ & $99.66 \mathrm{a}$ & $99.03 \mathrm{a}$ & $99.22 \mathrm{a}$ & $95.66 \mathrm{~b}$ & \\
\hline
\end{tabular}

Mean values of three replicates followed by the same letters in each column are not significantly different $(\mathrm{P}>0.05)$ (Duncan multiple range test). LSD at $(0.05 \%)$ for $\mathrm{A}=0.0715, \mathrm{~B}=1.012$, $\mathrm{AB}=1.753$

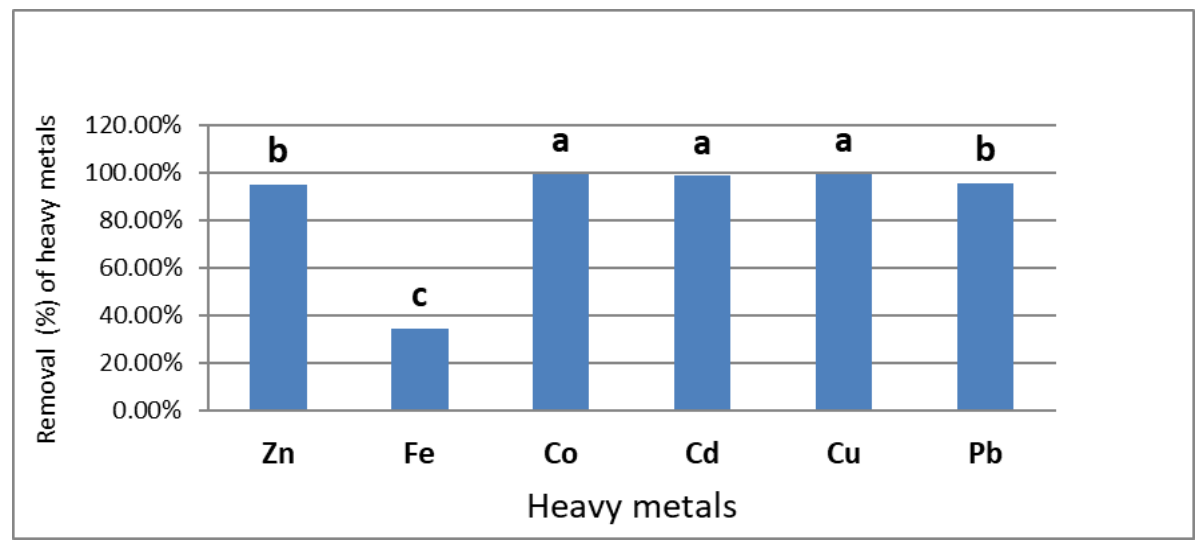

Figure 10. Average of the mean values $(B)$ of the different six heavy metals removal \% from $I W W)$. Values having the same alphabetical letter within each column are not significantly different at the 0.05 level according to (Duncan multiple range test) 
Also, similar data in Table 8 and Figure 11 revealed that a significantly higher removal efficiencies for $\mathrm{Co}^{+2}, \mathrm{Cd}^{+2}$ and $\mathrm{Cu}^{+2}$ when combined with bacterial isolates (Bacillus spp., B. cereus and B. altitudinis) without significant differences among them. The highest residual values and the lowest removal biosorption by bacterial isolates were recorded with $\mathrm{Fe}^{+2}$ similar results are recorded by Tuzen et al. (2007).

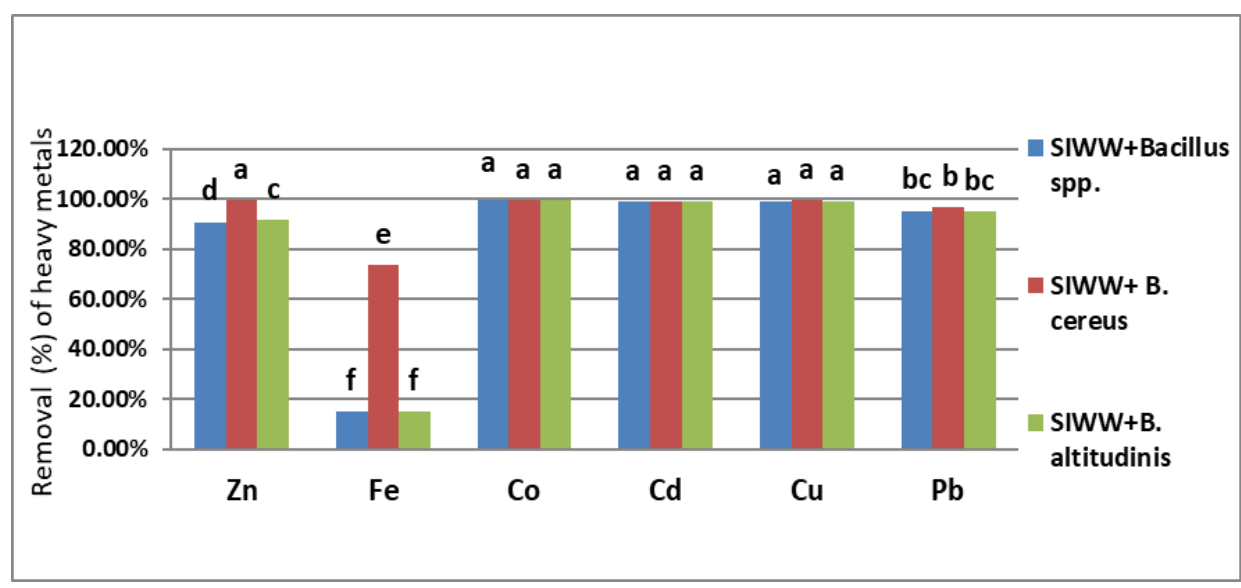

Figure 11. The interaction $(A B)$ effect between the treatments (SIWW + Bacillus spp., $S I W W+B$. cereus, $S I W W+B$. altitudinis) and six heavy metals removal \% of IWW. Values having the same alphabetical letter within each column are not significantly different at the 0.05 level according to (Duncan multiple range test). $I W W=$ Industrial Wastewater, SIWW = Sterile Industrial Wastewater

\section{Conclusion}

The isolation and identification of tolerant bacteria against six heavy metals $\left(\mathrm{Zn}^{+2}\right.$, $\mathrm{Fe}^{+2}, \mathrm{Co}^{+2}, \mathrm{Cd}^{+2}, \mathrm{Cu}^{+2}$ and $\mathrm{Pb}^{+2}$ ) give the new technology of bioremediation method. Among 30 isolates of Bacillus spp., 3 isolates exhibited more resistance effect against 6 heavy metals. These isolates were identified by morphological, biochemical characterization, molecular identification by using 16S rRNA gene and documented in GenBank as Bacillus sp. SMMAA-1 (LC472522), Bacillus cereus SMMAA-3 (LC472523), and Bacillus altitudinis SMMAA-4 (LC472524). These isolates are promising for further studies and can be used in bioremediation. The findings showed that bacteria present resistance of six heavy metals. B. cereus is more effective for removal efficiency percentage of six heavy metals $\left(\mathrm{Zn}^{+2}, \mathrm{Fe}^{+2}, \mathrm{Co}^{+2}, \mathrm{Cd}^{+2}, \mathrm{Cu}^{+2}\right.$ and $\left.\mathrm{Pb}^{+2}\right)(94.77 \%)$ from IWW than Bacillus spp. (83.19\%) and B. altitudinis (83.21\%). The highest removal efficiencies by Bacterial isolates were found with $\mathrm{Co}^{+2}, \mathrm{Cd}^{+2}$ and $\mathrm{Cu}^{+2}$ and the lowest removal biosorption were recorded with $\mathrm{Fe}^{+2}$. Data recommended to using of Bacillus cereus in bioremediation of heavy metals from industrial wastewater effluent especially with $\mathrm{Co}^{+2}, \mathrm{Cd}^{+2}$ and $\mathrm{Cu}^{+2}$ metals.

Acknowledgements. A special thank is paid to Prof. Dr. Nasser Sayed Youssef professor of Vegetables, Horticulture Research Institute, Agriculture Research Centre for his valuable continuous helpful, discussing the results, fruitful discussions, encouragement and necessary guidance during the long tenure of my study. 


\section{REFERENCES}

[1] Abbas, S. M., Kamel, E. A. (2004): Rhizobium as a biological agent for preventing heavy metal stress. - Asian J Plant Sci 3(4): 416-424.

[2] Ahemad, M., Khan, M. S. (2012): Effect of fungicides on plant growth promoting activities of phosphate solubilizing Pseudomona sputida isolated from mustard (Brassica compestris) rhizosphere. - Chemosphere 86(9): 945-950.

[3] Akhter, K., Ghous, T., Andleeb, S., Ejaz, S., Khan, B. A., Ahmed, M. N. (2017): Bioaccumulation of heavy metals by metal-resistant bacteria isolated from Tagetes minuta rhizosphere, growing in soil adjoining automobile workshops. - Pakistan Journal of Zoology 49(5).

[4] Altschul, S. F., Gish, W., Miller, W., Myers, E. W., Lipman, D. J. (1990): Basic local alignment search tool. - Journal of Molecular Biology 215(3): 403-410.

[5] Azad, A. K., Nahar, A., Hasan, M. M., Islam, K., Azim, M. F., Hossain, M. S., Rahman, M., Ojha, R. K., Mahmud, G. M. S., Kayes, R. (2013): Fermentation of municipal solid wastes by bacterial isolates for production of raw protein degrading proteases. - Asian J. Microbiol. Biotechnol. Environ. Sci. 15: 365-374.

[6] Bakar, A., Farid, A., Yusoff, I., Fatt, N. T., Othman, F., Ashraf, M. A. (2013): Arsenic, zinc, and aluminium removal from gold mine wastewater effluents and accumulation by submerged aquatic plants (Cabomba piauhyensis, Egeriadensa, and Hydrillaverticillata). Biomed Research International. ttps://doi.org/10.1155/2013/890803.

[7] Barrow, G. I. I., Feltham, R. K. A. (1993): Cowan and Steel's Manual for the Identification of Medical Bacteria. - Cambridge University Press, Cambridge.

[8] Carolin, C. F., Kumar, P. S., Saravanan, A., Joshiba, G. J., Naushad, M. (2017): Efficient techniques for the removal of toxic heavy metals from aquatic environment: a review. Journal of Environmental Chemical Engineering 5(3): 2782-2799.

[9] Chauhan, M., Solanki, M., Nehra, K. (2017): Putative mechanism of cadmium bioremediation employed by resistant bacteria. - Jordan Journal of Biological Sciences 10(2).

[10] Claus, D., Berkeley, R. C. W. (1986): Genus pseudomonas. - Bergey's Manual of Systematic Bacteriology 1: 140-219.

[11] Collins, C. H., Lyne, P. M., Grange, J. (1985): Microbiological Methods. - Butterworths, London.

[12] Dupont, W. D., Parl, F. F., Hartmann, W. H., Brinton, L. A., Winfield, A. C., Worrell, J. A., Plummer, W. D. (1993): Breast cancer risk associated with proliferative breast disease and atypical hyperplasia. - Cancer 71(4): 1258-1265.

[13] EPA (2005): Lead in Paint, Dust and Soil. - U.S. Environmental Protection Agency, Washington.

[14] Ghai, S., Sood, S. S., Jain, R. K. (2007): Antagonistic and antimicrobial activities of some bacterial isolates collected from soil samples. - Indian Journal of Microbiology 47(1): 77.

[15] Glickmann, E., Dessaux, Y. (1995): A critical examination of the specificity of the Salkowski reagent for indolic compounds produced by phytopathogenic bacteria. - Appl. Environ. Microbiol. 61(2): 793-796.

[16] Huang, F., Dang, Z., Guo, C. L., Lu, G. N., Gu, R. R., Liu, H. J., Zhang, H. (2013): Biosorption of $\mathrm{Cd}$ (II) by live and dead cells of Bacillus cereus RC-1 isolated from cadmium-contaminated soil. - Colloids and Surfaces B: Biointerfaces 107: 11-18.

[17] Jaishankar, M., Tseten, T., Anbalagan, N., Mathew, B. B., Beeregowda, K. N. (2014): Toxicity, mechanism and health effects of some heavy metals. - Interdisciplinary Toxicology 7(2): 60-72.

[18] Jeffery, G. I., Ley, R. E., Hamady, M., Lozupone, C., Turnbaugh, P. J., Ramey, R. R., Bircher, J. S. (2008): Evolution of mammals and their gut microbes. - Science 320(5883): 1647-1651. 
[19] Juni, E., Heym, G. A. (1986): Psychrobacter immobilis gen. nov., sp. nov.: genospecies composed of gram-negative, aerobic, oxidase-positive coccobacilli. - International Journal of Systematic and Evolutionary Microbiology 36(3): 388-391.

[20] Karelova, E., Harichova, J., Stojnev, T., Pangallo, D., Ferianc, P. (2011): The isolation of heavy-metal resistant culturable bacteria and resistance determinants from a heavy-metal contaminated site. - Biologia 66: 18-26.

[21] Kielak, A. M., Castellane, T. C., Campanharo, J. C., Colnago, L. A., Costa, O. Y., Da Silva, M. L. C. (2017): Characterization of novel Acidobacteria exopolysaccharides with potential industrial and ecological applications. - Scientific Reports 7: 41193.

[22] Kim, Y. G., Kang, H. K., Kwon, K. D., Seo, C. H., Lee, H. B., Park, Y. (2015): Antagonistic activities of novel peptides from Bacillus amyloliquefaciensPT14 against Fusarium solani and Fusarium oxysporum. - Journal of Agricultural and Food Chemistry 63(48): 10380-10387.

[23] Kumar, A. (2011): Mental health services in rural India: challenges and prospects. Health 3(12): 757-761.

[24] Lambert, M., Leven, B. A., Green, R. M. (2000): New Methods of Cleaning Up Heavy Metal in Soils and Water. Environmental Science and Technology Briefs for Citizens. Kansas State University, Manhattan, KS.

[25] Leonard, S. S., Bower, J. J., Shi, X. (2004): Metal-induced toxicity, carcinogenesis, mechanisms and cellular responses. - Molecular and Cellular Biochemistry 255(1-2): 310 .

[26] Malik, A., Jaiswal, R. (2000): Metal resistance in Pseudomonas strains isolated from soil treated with industrial wastewater. - World J Microbiol Biotechnol 16: 177-182.

[27] Marzan, L. W., Hossain, M., Mina, S. A., Akter, Y., Chowdhury, A. M. A. (2017): Isolation and biochemical characterization of heavy-metal resistant bacteria from tannery effluent in Chittagong city, Bangladesh: bioremediation viewpoint. - The Egyptian Journal of Aquatic Research 43(1): 65-74.

[28] Massoud, R., Hadiani, M. R., Darani, K. K., Hamzehlou, P. (2018): Bioremediation of heavy metals in food industry: application of Saccharomyces cerevisiae. - Electronic Journal of Biotechnology. https://doi.org/10.1016/j.ejbt.2018.11.003.

[29] Moradi, M. H., Eskandari, M., Hosseinian, S. M. (2015): Operational strategy optimization in an optimal sized smart microgrid. - IEEE Transactions on Smart Grid 6(3): 1087-1095.

[30] Murthy, S., Bali, G., Sarangi, S. K. (2012): Lead biosorption by a bacterium isolated from industrial effluents. - International Journal of Microbiology Research 4(3): 192-196.

[31] Mullen, M. D., Wolf, D. C., Ferris, F. G., Beveridge, T. J., Flemming, C. A., Bailey, G. W. (1989): Bacterial sorption of heavy metals. - Appl. Environ. Microbiol. 55(12): 31433149.

[32] Nagajyoti, P. C., Lee, K. D., Sreekanth, T. V. M. (2010): Heavy metals, occurrence and toxicity for plants: a review. - Environmental Chemistry Letters 8(3): 199-216.

[33] Nedialkova, D., Naidenova, M. (2005): Screening the antimicrobial activity of actinomycetes strains isolated from Antarctica. - Journal of Culture Collections 4: 29-35.

[34] Özdal, M., Özdal, O. G., Sezen, A., Algur, O. F. (2016): Biosynthesis of indole-3-acetic acid by Bacillus cereus immobilized cells. - Cumhuriyet Science Journal 37: 212-222.

[35] Pathak, M., Sarma, H. K., Bhattacharyya, K. G., Subudhi, S., Bisht, V., Lal, B. (2017): Characterization of a novel polymeric bioflocculant produced from bacterial utilization of n-hexadecane and its application in removal of heavy metals. - Frontiers in Microbiology 8: 170 .

[36] Priyadharshini, M., Kumar, S. R. (2016): Biodegradation of dairy wastewater using bacterial isolates. - International Journal of Modern Trends in Engineering and Science 3(7): 133-138. 
[37] Raja, S., Ravikrishna, R., Yua, X. Y., Leea, T., Chenc, J., Murugesand, K., Xinhua, S., Qingzhongc, Y., Kalliat, T., Collett, J. L. (2008): Fog chemistry in Texas-Louisiana Gulf Coast corridor. - Atmosph Environ J 42(9): 2048-2061.

[38] Rajendran, P., Gunasekaran, P. (2007): Nanotechnology for Bioremediation of Heavy Metals. - In: Singh, S. N., Tripathi, R. D. (eds.) Environmental Bioremediation Technologies. Springer, Berlin, Heidelberg, pp. 211-221.

[39] Rani, D., Moreira, M. M. (2010): Simulation-optimization modeling: a survey and potential application in reservoir systems operation. - Water Resources Management 24(6): 1107-1138.

[40] Şahin, Y., Öztürk, A. (2005): Biosorption of chromium (VI) ions from aqueous solution by the bacterium Bacillus thuringiensis. - Process Biochemistry 40(5): 1895-1901.

[41] Sardar, U. R., Bhargavi, E., Devi, I., Bhunia, B., Tiwari, O. N. (2018): Advances in exopolysaccharides based bioremediation of heavy metals in soil and water: A critical review. - Carbsohydrate Polymers 199: 353-364.

[42] Sneath, P. H., Mair, N. S., Sharpe, M. E., Holt, J. G. (1986): Bergey's Manual of Systematic Bacteriology. Vol. 2. - Williams \& Wilkins. Philadelphia, PA.

[43] Snedecor, G. W., Cochran, W. G. (1980): Statistical Methods. 7th Ed. - The Iowa State University Press, Ames.

Tuzen, M., Uluozlu, O. D., Usta, C., Soylak, M. (2007): Biosorption of copper (II), lead (II), iron (III) and cobalt (II) on Bacillus sphaericus-loaded Diaion SP-850 resin. AnalyticaChimicaActa 581(2): 241-246.

[44] Vijayadeep, C., Sastry, P. S. (2014): Effect of heavy metal uptake by E. coli and Bacillus sps. - Journal of Bioremediation \& Biodegradation 5: 238.

[45] Wang, K., Li, M., Hakonarson, H. (2010): ANNOVAR: functional annotation of genetic variants from high-throughput sequencing data. - Nucleic Acids Research 38(16): 164164.

[46] WHO (2003): The World Health Report: Shaping the Future. - World Health Organization, Geneva.

[47] World Health Organisation WHO (1984): Guidelines for Drinking Water Quality. WHO, Geneva, No.111.

[48] World Health Organization WHO (2006): Guidelines for the Safe Use of Wastewater, Excreta and Greywater: Wastewater Use in Agriculture (Volume II). - WHO, Geneva.

[49] Yilmaz, M., Soran, H., Beyatli, Y. (2006): Antimicrobial activities of some Bacillus spp. strains isolated from the soil. - Microbiological Research 161(2): 127-131.

[50] Zhou, X., Borén, J., Akyürek, L. M. (2007): Filamins in cardiovascular development. Trends in Cardiovascular Medicine 17(7): 222-229.

[51] Ziagova, M., Dimitriadis, G., Aslanidou, D., Papaioannou, X., Tzannetaki, E. L. (2007): Comparative study of Cd (II) and Cr (VI) biosorption on Staphylococcus xylosus and Pseudomonas sp. in single and binary mixtures. - Bioresour. Technol. 98: 2859-2865. 